\title{
When Conditionals Lack Conditionality: The Semantics of Biscuit Conditionals in some Selected Texts from the Holy Quran and the Qudsi Hadiths: A Default Semantics-Theoretic Perspective
}

\author{
Ayman F. Khafaga \\ (Faculty of Arts, Suez Canal University)
}

\begin{abstract}
Drawing on Jaszczolt's (2005) Default Semantics theory, and inspired by Austin's (1961, p. 158) original example: "There are biscuits on the sideboard if you want some," this paper attempts a semantic analysis of Biscuit Conditionals (BCs) in some selected texts from the Holy Quran and the Qudsi Hadiths, with the intention to explore how this type of conditionals communicates discourse meanings other than conditionality. The main objective of this paper is to show how BCs can semantically be represented to communicate non-conditional meanings within the framework of Default Semantics, a contextualism-oriented and truthconditional approach that aims to identify the primary meanings pertaining to utterances. Four research questions are presented here: first, what are the different types of BCs presented in the selected texts from the Holy Quran and the Qudsi Hadith? Second, why are the selected constructions considered Biscuit Conditionals not any other type of conditionals? Third, what are the didactic purposes conveyed by BCs in the selected data? Fourth, how are BCs semantically represented to convey non-conditional meanings within the framework of a religionoriented type of communication, and in light of a theory of discourse meaning? In light of Default Semantics, the paper concludes that Biscuit Conditionals in the selected data lack conditionality on the level of their intended meanings, and assign the discourse functions of fact-confirmers, information-notifiers, sympathy-instigators, invitation-motivators, discourse-relievers and offer-activators that function as conduits of religious didacticism.
\end{abstract}

Keywords: biscuit conditionals; default semantics; merger representations; intended meanings; religious didacticism; the Holy Quran; the Qudsi Hadiths 


\section{مستخلص البحث باللغة العربية}

تحاول هذه الورقة البحثية إجراء تحليل دلالي لنمط معين من انماط الثرط في اللغة الانجليزية و هو Biscuit Conditionals في بعض من النصوص المختارة من القرآن الكريم و الأحاديث

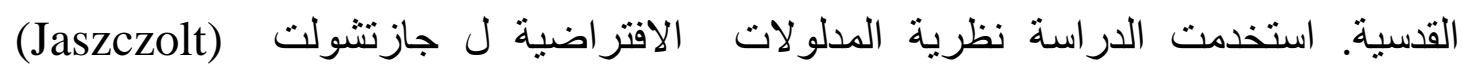

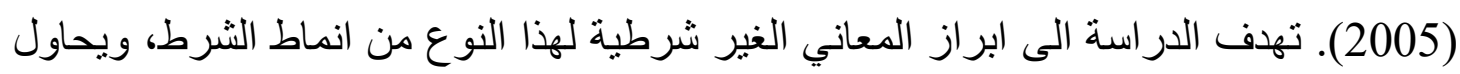

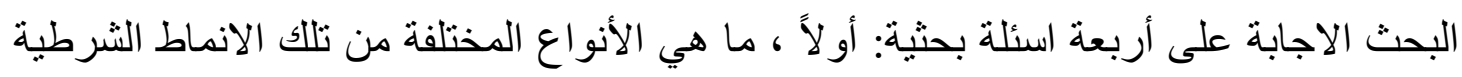

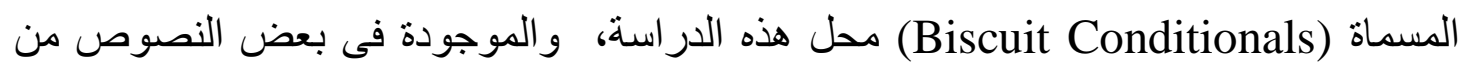

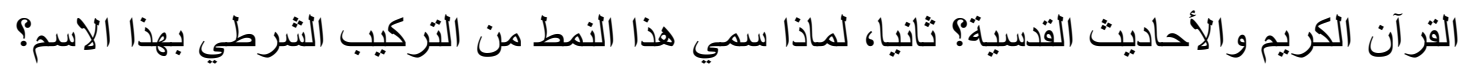

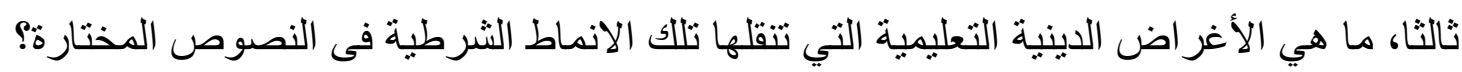

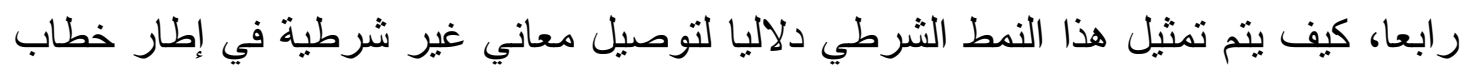

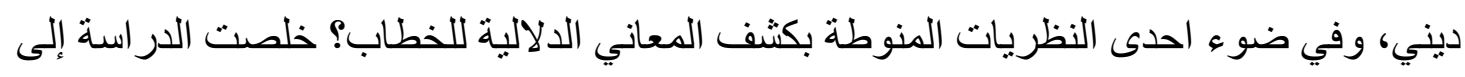
أن النمط الثرطي محل هذه الدر اسة (Biscuit Conditionals) لا يؤدي معان شرطية و انما

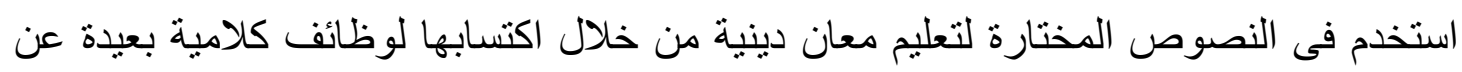

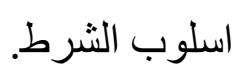

الكلمات المفتاحية: التعبير ات الثرطية ذات المدلول الغير شرطي، نظرية المدلو لات

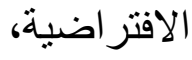
المعاني الاساسية من الخطاب، القران الكريم، الأحاديث القسية 


\section{Introduction}

Austin's (1961, p. 158) original example: "There are biscuits on the sideboard if you want some" has always been a source of inspiration for much research on what is called Biscuit Conditionals (BCs), a term which is given to utterances that constitute conditional forms but convey nonconditional meanings. This type of conditionals does not communicate conditionality because, as noted by von Fintel (2011), the truth of the consequent does not depend on the truth of the antecedent. However, in light of this paper, they are used to convey didactic messages. These messages can be explored by uncovering the primary meanings (the intended meaning of the speaker) this type of conditionals implicitly carries beyond its explicitly conditional structures.

The main objective of this paper is to investigate the different linguistic manifestations of Biscuit Conditionals (BCs), and the way they are semantically represented to communicate certain discourse functions other than conditionality within a divine ethical context of religion. This goal is pursued within the scope of Jaszczolt's (2005) Default Semantics, a semantically contextualist and truth-conditional theory that functions to identify the different meanings pertaining to utterances. The reason why this theory is adopted for the analysis of BCs in the selected data lies in the fact that one of its main goals is to help recognize the intended meanings arrived at by sources of information other than what is superficially expressed by the linguistic forms. The state of going beyond the linguistic expressions towards other meanings is totally relevant to the study of BCs since the latter, however conditional in form, communicates non-conditional meanings.

The research questions of this paper are: first, what are the different types of BCs presented in the selected texts from the Holy Quran and the Qudsi Hadith? Second, why are the selected constructions considered BCs, not any other type of conditionals? Third, what are the didactic purposes conveyed by BCs in the selected data? Fourth, how are BCs semantically represented to convey non-conditional meanings within the framework of Default Semantics theory, and in light of a religion-oriented type of communication?

The remainder of this paper is structured as follows. In section 2, the paper presents the literature review and the theoretical framework, by offering a theoretical background to the meaning of conditionals and their types with a special focus on Biscuit Conditionals, and then it moves to provide a theoretical discussion on Default Semantics theory, its framework, tenets, objectives, and its relevance to the study of Biscuit Conditionals. Section 3 sheds light on the methodology of the study, in which data collection, data description and procedures adopted in data 


\section{When Conditionals Lack Conditionality: The Semantics of Biscuit Conditionals in some Selected Texts from the Holy Quran and the Qudsi Hadiths: A Default Semantics-Theoretic Perspective}

analysis will be presented. Section 4 is dedicated to the analysis of the selected data. Section 5 discusses the findings of the paper. Section 6 concludes the paper and suggests some ideas for future research.

\section{Theoretical framework and literature}

\subsection{Conditionals}

Conditionals have been discussed from different perspectives; by approaching the semantic basis upon which they are divided into factual, predictive, hypothetical, and counterfactual, and the different meanings pertaining to each type (Beck, 1997; Yule, 1998; Bennett, 2003); by analyzing the way through which various conditional constructions are used to communicate predictions through time, knowledge and causation (Dancygier, 1998); by investigating their different syntactic forms and truth conditions (Declerck \& Reed, 2001; von Fintel, 2009, 2011; Schulz, 2015); by focusing on the mechanisms of recognizing both the secondary and the primary meanings they communicate (Jaszczolt, 2009); and by highlighting their pragmatic and cognitive dimensions in communicating meaning (van der Auwera, 1986, 1997; Byrne \&Johnson-Laird, 2010; Elder \& Jaszczolt, 2016).

von fintel (2011) argues that a conditional is a sentence which consists of two parts: an "antecedent" and a "consequent" (p. 1516); the former, for him, refers to the proposition of the if-clause, whereas the latter represents the proposition of the main clause, and it is sometimes "marked with then" (ibid.). von Fintel (ibid., p. 1516) lists different structures other than using the operator 'if' through which conditional meanings are communicated. Among them are: 'Inversion' as in "had he admitted his guilt, he would have gotten off easier"; starting with the 'imperative' as in "take another step and I'll knock you down"; and sometimes by using 'without' at the beginning of the sentence as in "without you, I would be lost" (ibid. p. 1516).

von Fintel (2011) identifies four types of conditionals: Biscuit Conditionals (also: metalinguistic conditionals, non-conditional conditionals, speech act conditionals, illocutionary conditionals, and relevance conditionals), factual conditionals, indicative conditionals and subjunctive conditionals. For von Fintel (ibid. p. 1517), Biscuit Conditionals "do not state in any sense conditions under which the consequent is true," and are used to communicate discourse functions other than conditionality. He quoted Austin's (1961, p. 158) "there are biscuits on the sideboard if you want them" as an example of this type. Factual conditionals (also: premise conditionals) are conditionals that "often echo someone else's introduction of the antecedent" (von Fintel, 


\section{Ayman F. Khafaga}

2011, p. 1517). In von Fintel's example: "If it is indeed that late, we should leave," it is obvious that the consequent totally depends on what is previously stated in the antecedent. The other two types of conditionals are indicative and subjunctive conditionals. For von Fintel (ibid.), the main difference between the two types lies in the truth conditionality of the antecedent. That is, in indicative conditionals "the truth of the antecedent is an open issue," whereas subjunctive conditionals "convey that the antecedent is false" (p. 1518). In his examples: "If Grijpstra played his drums, de Gier played his flute" and "If Grijpstra had played his drums, de Gier would have played his flute," the antecedent of the former example is inferred to be true, while the antecedent in the latter is supposed to be false.

Schulz (2015) tries to approach the meanings pertaining to conditionals by assuming that the semantics of conditional sentences are influenced by different factors: philosophical, cognitive and linguistic. In seeking the semantic meanings of conditionals, Schulz (ibid.) focuses on two problems; the first is concerned with "the relation between the logical form often assumed for conditional sentences and the actual form of these sentences" (p. 805, italics in original); and the second is related to the difference between "indicative and subjunctive conditionals" (ibid., p. 806). She clarifies that the logical form of conditionals constitutes two elements: an antecedent and a consequent, arguing that there is a referential relationship between the proposition in the if-clause (antecedent) and that in the consequent clause. As for the distinction between indicative and subjunctive conditionals, Schulz (ibid., p. 809, capitals in original) maintains that it lies in "the finite verb," which, in the subjunctive type, "is marked for the Simple Past" in the antecedent and "is a modal verb" in the consequent. These two linguistic markers of subjunctive conditionals, for her, are missed in indicative ones (ibid.).

\subsubsection{Biscuit Conditionals}

Much research has been conducted on Biscuit Conditionals (Iatridou, 1991; von Fintel, 1997, 2011; DeRose \& Grandy, 1999; Siegel, 2006; Franke, 2007; Predelli, 2009; Joh, 2011; Douven, 2012; Swanson, 2013; Rhee, 2014; Francez, 2015; Schulz, 2015; Skovgaard-Olsen, 2016; Zakkou, 2017; Rieser, 2017), among others. These studies agree that Biscuit Conditionals go beyond conditionality towards other primary meanings. These meanings, this paper argues, can be arrived at by the application of Default Semantics theory, particularly its merger representations dimensions (see Subsections $2.3 \& 2.4$ below).

Biscuit Conditionals is a term derived from Austin's (1961, p. 158) original example "there are biscuits on the sideboard if you want some." Within this type of conditionals, according to Rieser (2017, p. 109), "the 


\section{When Conditionals Lack Conditionality: The Semantics of Biscuit}

Conditionals in some Selected Texts from the Holy Quran and the Qudsi Hadiths: A Default Semantics-Theoretic Perspective

information the consequent [proposition of the main clause] provides is relevant for the addressee only in case the antecedent [proposition of the if- clause] holds." Biscuit Conditionals, thus, are a particular type of conditionals in which "the if-clauses specify the circumstances in which the consequent is relevant...not the circumstances in which it is true" (Iatridou, 1991, p.51).

Biscuit Conditionals have also been approached in terms of their illocutionary acts; that is, "the if clause appears to apply to the illocutionary act performed in uttering the main clause, rather than to its propositional content" (Siegel, 2006, p. 167, italic in original). This, Siegel (ibid.) argues, means that Biscuit Conditionals cease to act as antecedents for the consequents in their main clauses, and, thus, go beyond their ordinary conditional use towards other purposes. Siegel's approach to Biscuit Conditionals emphasizes two things: first, the surface conditionality of their forms; and, second, the unrelated relationship between BCs antecedents and their consequents.

For Franke (2007), Biscuit Conditionals connect two meanings that are conditionally unrelated. He argues that $\mathrm{BCs}$ do not communicate a conditional meaning as is the case for what he terms "standard conditionals" (ibid., p. 92); that is, they convey the non-conditional truth of their consequents, and, consequently, allow for discourse functions other than conditionality to operate in discourse. Franke (ibid.) proceeds that the antecedents and the consequents in BCs are "epistemically independent for an agent" (p. 91, italics in original). In this sense, the truth or falsity of the proposition in the antecedent is not enough to decide the truth or falsity of the proposition in the consequent. This epistemic independence, for him, depends on the speaker's degree of truthfulness in asserting 'if $\mathrm{p}$, q' state. Franke (ibid.) also postulates that the notion of relevance, which is supposed to exist between antecedents and consequents in $\mathrm{BCs}$, is not enough to create a successful meaning beyond this type of conditionals. However, he maintains, there should be a state of intelligibility between $\mathrm{BCs}$ ' antecedents and consequents which guarantees that "the consequent is understood appropriately" (ibid., p. 94). Here, Franke prefers to describe Biscuit Conditionals as "intelligibility conditionals" rather than "relevance conditionals" (ibid., p. 94, italics in original). Thus, in his view, it is not only for BCs' antecedents to be relevant to assure the right interpretation for their consequents, but also to be intelligible enough to "coordinate a proper reception of the consequent between conversationalists" (ibid., p. 95). 


\section{Ayman F. Khafaga}

As for truth conditions, von Fintel (2011) states that in BCs the ifclause does not influence the truth conditions of the consequent clause, but it operates at a speech act level in discourse. For him (ibid.), the truth possibility of the if-clause functions to cast certainty on the proposition encoded in the consequent, but it does not change its truth conditions. The concept of meaning realization is called "conditional assertion" (ibid., p. 1525), and can often be attached to BCs since the truth conditions of their consequents are not contingent on that of the if-clauses. In other words, the if-clauses in BCs do not encode any conditional meaning that can restrict the realization of the propositional content of the consequent. Importantly, to Lycan (2001), the idea that conditionals have truth conditions or lack them is not something that is attached to the construction assigned by the conditional itself. Rather, it relates to the extent to which the speaker believes/disbelieves in the realization of the content expressed in the consequent.

Pragmatically, van Canegem-Ardijns and van Belle (2008) classify conditionals into different types, among which is BCs. They adopt van der Auwera's (1986, p.199, cited in van Canegem-Ardijns \&van Belle, 2008, p. 366 ) term "commentative conditional speech acts" to describe $\mathrm{BCs}$ and other types of conditionals that, for them, "fail to trigger if not $p$, then not $q$ as their inference" (van Canegem-Ardijns \&van Belle, 2008, p. 366 , italics in original). They maintain that the antecedents of BCs among the other types of commentative conditional speech acts function as "politeness or opting out devices" (ibid., p. 366). They proceed to divide conditionals into "conditional speech acts," in which a speech act is performed "conditionally"; and "speech acts about conditionals," where a speech act is performed "categorically" (ibid, p. 370). They believe that $\mathrm{BCs}$ belong to the second type because their antecedents do not appeal to a condition to perform the intended speech act. However, in their words, the antecedents in this type (i.e. speech acts about conditionals) refer to "a particular conversational rule or politeness maxim relevant to the intended speech act" (ibid., p. 371). Thus, in view of van CanegemArdijns and van Belle (ibid.), the concept of relevance between the antecedent and the consequent in $\mathrm{BCs}$ is crucial in shaping their compositional content and, therefore, in recognizing the speaker's intended meaning.

In consonance with Bhatt and Pancheva (2005), Zakkou (2017) postulates that Biscuit Conditionals are marked by the absence of conditional 'then', arguing that the reason for this is that the antecedent in BCs does not specify situations in which the consequent is true. This unspecification of situation, for her, is due to two reasons: the first is that "the consequent is presumed true anyway" (ibid., p. 84); that is, the 


\section{When Conditionals Lack Conditionality: The Semantics of Biscuit Conditionals in some Selected Texts from the Holy Quran and the Qudsi Hadiths: A Default Semantics-Theoretic Perspective}

consequent is true even if the antecedent is false; and the second is that "the consequent is not taken to be true even if the antecedent is true" (ibid., p. 85). Zakkou (ibid.) proceeds that the insertion of 'then' in front of the consequent of a biscuit conditional changes the meaning as well as the category of the conditional. Thus, the insertion of 'then' before the consequent in her example 'if you are thirsty, then there is beer in the fridge' allows the antecedent to specify the conditions under which the consequent is true. By this way it violates the truth-dependence principle of $\mathrm{BCs}$, and, therefore, changes the category of the conditional to be a hypothetical rather than a biscuit one.

In an attempt to present a semantic analysis to Biscuit Conditionals, Predelli (2009, p. 293) builds his analysis on two main principles pertaining to this type of conditionals: "the if-clause in a biscuitconditional is truth-conditionally idle, but it 'qualifies' the speech-act in question." Predelli (ibid.) presents three constraints that should be considered in order to provide a correct semantic account for BCs. These are: the speaker's assertion of the proposition in the consequent is conditional upon the addressees' desires, BCs motivate the proposition in the consequent, and the if-clause part of the conditionals, sometimes, is opened for other syntactic structures such as 'if you want some' that function to test the truth conditions of the construction. Predelli (ibid., p. 294) argues that in searching for the appropriate reading for BCs, there are some "semantic contributions" to the right interpretation of utterances, represented in different indicative words, phrases and sentences that function to derive the "conversationally relevant use" of BCs (ibid., p. 294).

\subsection{Jaszczolt's Default Semantics}

Default Semantics theory enters the arena of linguistics in the hands of Kasia Jaszczolt with her book entitled Default Semantics: Foundations of a Compositional Theory of Acts of Communication which was published in 2005. In her book, Jaszczolt (2005) lays down the principles and objectives of a new semantic theory that is mainly concerned with meaning in discourse as well as the main principles of its cognitive interpretation. Jaszczolt (2005, p. xvi) argues that Default Semantics combines two incompatible theses as its assumptions: "(i) that truth value can be predicated of utterances (acts of communication), that is, that pragmatic input contributes to the truth conditions; and (ii) that the theory of meaning of utterances and discourses is a compositional, semantic theory." She also casts a special emphasis on the different truthconditional approaches and the speakers' intentions, and the way they are 


\section{Ayman F. Khafaga}

incorporated to produce the cognitive meaning of discourse, i.e. meanings that are not presented in the surface structure of the linguistic expressions, but are formulated by the combination of certain elements, such as world knowledge, pragmatic inference, and social and cultural criteria. Here, unlike Discourse Representation Theory (Kamp, 1981) which allows syntactic constructions a great part to play in meaning interpretation; Default Semantics neglects the role of syntactic structures in utterance interpretation. Utterances in Default Semantics are "guides to the full, intended proposition that has to be inferred" (ibid., p. 13).

According to Jaszczolt (2011, p. 14), the word 'default' means "the interpretation that is arrived at automatically" which, in light of Default Semantics, is targeted by means of a number of contextual information sources that are incorporated to arrive at the intended meaning of the speaker. In this sense, Default Semantics is also a theory of intentional meaning that aims to bridge the gap between the intended meaning of the speaker and the meaning recovered by the hearer in context. Jaszczolt (2005) argues that her theory derives its main foundations from "Gricean" and "post-Gricean pragmatics" since it shows "some basic familiarity with Gricean, intention-based pragmatics" (p. xi). It is "a theory of meaning of acts of communication" and "a theory of meaning of discourses" because, she emphasizes, acts of communications are the way through which meanings are derived. These meanings, for Jaszczolt (ibid.), can be represented by the merger of certain sources of information that play a part in arriving at the primary meanings of utterances. This process is called "merger representations" (p. 4), and will be discussed in Subsection 2.4 below.

Default Semantics shares some features with Discourse Representation Theory in the sense that both leave a place for social and cultural conventions for default interpretation. These conventions, for Levinson (2000, cited in Jaszczolt, 2005), are based on the four Gricean maxims of conversation: quantity, quality, manner and relation. As such Default Semantics emphasizes the incorporation of different sources in discourse meaning. One main source is the truth conditions of the utterance, which, for Jaszczolt (2005, p. 7), mean "the one that the speaker intended to communicate rather than the truth conditions of the sentence alone."

The view of analyzing meaning in terms of the truth conditions of the utterance is also argued for by Recanati (2004) who postulates that the intended meaning of the speaker is derived from certain pragmatic inputs that have a significant part in determining the truth conditions of the content of utterances. These pragmatic factors, for him, operate contextually in discourse during a process which he terms 


\section{When Conditionals Lack Conditionality: The Semantics of Biscuit}

Conditionals in some Selected Texts from the Holy Quran and the Qudsi Hadiths: A Default Semantics-Theoretic Perspective

"contextualism" (ibid., p. 154), in which pragmatic criteria lead to the speaker's meaning of an utterance. Obviously, as Jaszczolt (2005) notes, Default Semantics comes to terms with Recanati's contextualism in terms of the "truth-conditional content" (p. 7) as one source of meaning interpretation. However, it rejects the idea that speaker's meanings can only be derived through pragmatic contextualism. Default Semantics, then, is a theory that is concerned with "meaning of discourses, has merger representations as truth-conditionally evaluable units, gives no prominence to the linguistic component (combination of word meaning and sentence structure), and, at this level of merger representations, is taken to be fully compositional" (Jaszczolt, 2005, pp. 81-82, emphasis in original).

\subsection{Biscuit Conditionals in Default Semantics}

Now comes the role that can be played by Default Semantics in Biscuit Conditionals. Two questions are in order here: Is Default Semantics relevant to the study of conditionals in general, and BCs in particular? If so, how does it contribute to the semantics of BCs? Based on what is previously stated in the literature above that BCs lack conditionality in the sense that the truth conditions of their consequents are not contingent on that of the antecedents, and given the assumption that BCs communicate other primary meanings that are not directly expressed in their linguistic forms, together with Jaszczolt's (2005) argument that Default Semantics aims at revealing the speaker's intended meaning by means of merger representations analysis, it follows then that Default Semantics is relevant to the study of BCs because it "allows us to formally represent the main meaning intended by the speaker and recovered by the addressee" (Elder \& Jaszczolt, 2016, p. 47).

Within the framework of Default Semantics, primary (intended) meanings can be arrived at by means of the different dimensions of its merger representations approach. These representations are based on sources of meaning information: social, cultural, cognitive and pragmatic. Importantly, the primary meanings recognized by virtue of merger representations constitute, in most cases, syntactic constructions different from the main linguistic forms of the uttered sentences. That is because the compositionality of the primary meaning comes as a result of a complete dependence on "extralinguistic sources of information" (Elder \& Jaszczolt, 2016, p. 47). Therefore, specific meanings (i.e. other than the conditional) are expected to be the appropriate interpretation of direct and/or indirect BCs constructions: direct in the sense that they constitute the conditional operator 'if' in their antecedents; and indirect in the sense 


\section{Ayman F. Khafaga}

that their implicit conditionality is expressed by conditional operators other than 'if', such as using imperatives. Accordingly, this theory manages to achieve what Jaszczolt (2005) calls "semanticizing truthconditional pragmatics" (p. xx): truth conditional in the sense that "truthconditional content is the output of all the sources of meaning information that can be consulted in the processing of discourse" (ibid, p. xx).

Elder and Jaszczolt (2016) adopt Jaszczolt's (2005) Default Semantics theory to argue for the possibility of introducing what they call "a pragmatic category of conditionals" (p. 37), through which conditional meanings are not only based on the mere syntactic form of the expression itself, but rather on certain pragmatic considerations. They postulate that conditional thought can be communicated by means of conditional or non-conditional structures. They maintain that using "radical contextualism" (ibid., p. 39) functions to combine the different uses of conditional constructions with the various means of communicating conditional thought. This radical contextualist approach, for them (ibid.), highlights the role of context in "determining the truth conditional content of an utterance," and in "helping to identify the main speech act intended by the speaker" (p. 39) without any considerations to the syntactic construction of the sentence.

The significant role of context in the interpretation of conditional sentences emphasizes the assumption that contexualism is based on information that is not encoded in the linguistic expression of the conditional structures themselves. Meanings are derived from other contextual factors surrounding the sentence, such as cultural, social and cognitive considerations. These factors are encapsulated in Jaszczolt's (2005, p. xvii ) "merger representations" that play a substantial part in what is termed "compositionality of content" (ibid., p. 76), or what Elder and Jaszczolt $(2016,36)$ call "interactive compositionality"; that is, "compositionality predicated of acts of communication rather than sentence structures" (ibid., p. 37).

Elder and Jaszczolt (2016, p. 49) identify six types of sentences that can be used to communicate conditional thought:

(C1) is the typical case: a standard, overt conditional with a strong, primary conditional meaning; (C2) is a conditional sentence with a primary meaning that is not conditional; (C3) is an example of a sentence that does not have a conditional form but whose primary meaning is conditional; (C4) is again an example of a sentence that does not have a conditional form but whose primary meaning is not conditional either; instead, it has a secondary conditional meaning; (C5) is an instance of an incomplete conditional sentence where the conditional meaning 


\section{When Conditionals Lack Conditionality: The Semantics of Biscuit}

Conditionals in some Selected Texts from the Holy Quran and the Qudsi Hadiths: A Default Semantics-Theoretic Perspective

is primary; and finally (C6) is an instance of an incomplete conditional sentence where the conditional meaning is secondary (my emphasis).

As indicated in the quote above, (C2) represents conditionals that constitute conditional forms but carry non-conditional meanings (this type represents direct $\mathrm{BCs}$ in light of this paper). Also, (C4) represents sentences that comprise non-conditional forms and meanings (this type represents indirect $\mathrm{BCs}$ in light of this paper). The two types, i.e. the direct and the indirect BCs, will be handled in the analysis section (see Section 4 below).

\subsection{Merger representations and the compositionality of meaning}

According to Jaszczolt (2005), merger representations are "semantic representations" (p.73) in the sense that they are "representations of meaning of an utterance" (ibid., p. 73); that is, the intended meaning of the speaker. For her, merger representation is introduced to offer a proper description of the compositional and contextual meaning of a given sentence. She (ibid., p. xvi) maintains that they are called merger representations because they "combine (merge) information from word meaning, sentence structure, conscious pragmatic inference, and various kinds of default interpretations" to arrive at the intended meanings pertaining to utterances (discourse). Within the scope of these merger representations, Jaszczolt (2010) argues, default meanings are conceived of as "cognitive defaults," which are produced by the process of human thinking; and "social-cultural defaults," which stem from the way culture and society are shaped (p. 197).

For Jaszczolt (2005, p. 22), a merger representation "reflects the meaning with which a sentence, a sub-sentential expression, or a multisentence string was used in a discourse," and, therefore, it pertains to "what is said in the sense of the meaning situated in context" (ibid., p. 22). Merger representations have to be "dynamic" (ibid., p. 28) in the sense that they should concern with "context change" (ibid., p. 28) that can be conducted by their allowance for pragmatic and semantic sources of information, which in turn leads to the compositionality of utterances' meanings. Again, Default Semantics, in searching for the intended meaning of utterances which is realized by means of its merger representations dimensions, emphasizes the importance of extralinguistic sources in meaning interpretation process. The semantics of sentences in Jaszczolt's (2010) view, therefore, can be read in a contextualist way. 


\section{Ayman F. Khafaga}

Within the scope of Default Semantics, compositionality is perceived on the level of the content of the utterance. The content here means the meaning that is recognized by the hearer from the act of communication, and in this way, Jaszczolt (2005, p. 80) argues, compositionality means "the meaning of the acts of communication" that can be grasped "on the level of merger representations." As such, a compositional meaning of an utterance is the product of a combination of sources, all of which come under merger representations level. These sources, for Jaszczolt (ibid.), are sources of meaning information that contribute to the merger, and are interacting to form the intended meaning of the speaker in an act of communication. Thus, one salient fact about the compositional meaning of an utterance is that it is formed at the level of merger representations, not at the level of linguistic semantics, that is, the combination of word meaning and sentence meaning. In this sense, the merger representations level should constitute "contextual upgrading of informational content" which "is accounted for by means of pragmatic inference, cognitive defaults, and social-cultural defaults" (ibid, p. 82). Thus, meaning is not "principally syntax-based," but "it is based on multiple sources of information" (ibid., p. 94).

For Jaszczolt (2010, p. 198), Default Semantics identifies five sources of information that contribute to a merger representations analysis and, consequently, lead to discover the primary intended meanings of utterances. These sources are: (i) word meaning and sentence structure (WS); (ii) world knowledge (WK); (iii) situation of discourse (SD); (iv) properties of human inferential system (IS); and (v) stereotypes and presumptions about society and culture (SC). These sources, according to Elder and Jaszczolt (2016), are responsible for generating the primary meanings (intended meaning) of the speaker. In the case of BCs, these primary meanings are non-conditional meanings arrived at by means of a number of default representations of utterances' contents that include, (i) compositional meaning of the sentence; (ii) cognitive defaults; (iii) conscious pragmatic inference; and (iv) social-cultural defaults (Jaszczolt, 2005, p. 57). Further, Jaszczolt (ibid., p. 52) refers that there are "default anaphoric links" that also help to arrive at the relevant meanings of utterances. Within Default Semantics, these anaphoric links are "presuppositional" links (ibid., p. 157) that contribute indicatively in meaning compositionality.

In his attempt to comment on the role of merger representations and its identified sources of information in meaning interpretation, Capone (2011) finds it relevant to discuss the relationship between Jaszczolt's (2005) Default Semantics and Sperber and Wilson's (1995) Relevance Theory. He, therefore, argues that while Default Semantics focuses on 


\section{When Conditionals Lack Conditionality: The Semantics of Biscuit Conditionals in some Selected Texts from the Holy Quran and the Qudsi Hadiths: A Default Semantics-Theoretic Perspective}

certain sources of information through which addressees can provide meanings of utterances, Relevance Theory focuses on the processing of such sources of information. Capone maintains that there is a relationship between the two theories in the sense that both of them depend on what he calls "modularity of mind" (ibid., p. 1741), in which cognitive knowledge plays a part in identifying utterances' meanings. He proposes a module which he terms "Mind-reading module" (ibid., p. 1741, capital in original), within which the process of inference operates actively towards the understanding of utterances. Such an inferential process, for him, is considered one of the principles of Default Semantics and Relevance Theory. Further, Capone (2011) states that merger representations, being one of the main principles of Default Semantics that guarantees compositionality of utterances' meanings, are not the only source through which intended meanings are identified. However, contextual elements as well as pragmatic inferences have a role to play in utterance interpretation. He relates such inferential process to the ability of recognizing the intended meaning of the speaker. He, therefore, casts emphasis on the centrality of intentions in the process of interpreting utterances, or as he puts it, "a reaching out towards the speaker" (ibid., p. 1743 , italics in original).

\section{Method}

\subsection{Data: Collection \&description}

The data used for analysis in this paper consists of two types. The first type constitutes 9 verses, selected from 7 chapters from the Holy Quran, and distributed as follows: 1 verse from Surat Al-Baqarah (The Cow), 1 verse from Al-e-Imran (The Family of Imran), 3 verses from Annisa (Women), 1 verse from Al-Maeda (The Table), 1 verse from Yunus (Jonah), 1 verse from Hud (Hud), and 1 verse from An-Nahl (The Bee). The selected verses are marked as indicative in the study of Biscuit Conditionals discussed in this paper. The second type is one of the Qudsi Hadiths (Hadith No. 24) that was related by Muslim, at-Tirmidi, and Ibn Majah. The selected Hadith was adopted from Ibrahim and JohnsonDavies's (1976). The translated version, which is adopted in data analysis, consists of 336 words, distributed in 10 long sentences, and all of them start with the phrase 'O My servants'.

The reasons why the verses as well as the Qudsi Hadith are selected in particular are: (i) they carry Biscuit Conditionals, either explicitly or implicitly; (ii) their semantic compositionality serves religious didacticism; (iii) they are semantically structured in a way that goes 


\section{Ayman F. Khafaga}

beyond conditionality towards other discourse functions, such as giving information, confirming facts, motivating invitations or activating offers. Consequently, this paper tries to show the extent to which BCs communicate discourse functions that go beyond conditionality towards religious didacticism.

\subsection{Procedure}

This paper passes through two main procedural stages. The first stage is a preliminary step for stage two, and is dedicated to inspect, identify and select the verses and the Qudsi Hadith relevant to the study of Biscuit Conditionals. This stage is divided into two parts. The first part is concerned with the verses that are selected from the Holy Quran. In this part, all chapters of the Holy Quran are carefully read and a number of specialists in the field of Islamic Studies are consulted concerning the different types of conditional structures used in the Holy Quran. This stage ends with highlighting only 9 verses that are indicative in demonstrating BCs, either directly or indirectly. This indicates that this paper might have some limitations concerning its ability to identify and select all verses carrying BCs structures in the Holy Quran. Similarly, in the second part of stage one, a collection of forty-two Qudsi Hadiths is totally read. Only one Hadith is highlighted as having BCs: Hadith No. 24. Both the selected verses and the Qudsi Hadith are collected and written in a word office file to be ready for the analysis process. The analysis starts in stage two, through which emphasis is casted on the way through which $\mathrm{BCs}$ are semantically structured and/or restructured by means of merger representations to communicate non-conditional meanings and discourse functions other than conditionality. Also in this stage, the way through which $\mathrm{BCs}$ are used as conduits of religious didacticism is linguistically evidenced and analytically demonstrated in light of a theory of discourse meaning: Default Semantics.

Importantly, the selected verses of the Holy Quran are quoted in their original form of production (i.e. standard Arabic), and are accompanied with the English translation which is adopted from Pickthall's (1930/1985). Despite the fact that there are many scholars who attempted many translations of the meaning of the Holy Quran, Pickthall's translation is selected here because of its popularity that are due to two reasons: first, it is "elegant in presentation," and, second, it is "free from the errors" found in the Orientalists' translations (Kidwai, 2017, p. 235). Also, the English translation of the selected Hadith is adopted from Ibrahim and Johnson-Davies's (1976). It is important to mention here that the word (Allah) is used instead of (God) throughout this paper because it is more in conformity with Islam and more relevant to the contextual atmosphere of this paper, particularly when one knows that all texts 


\section{When Conditionals Lack Conditionality: The Semantics of Biscuit Conditionals in some Selected Texts from the Holy Quran and the Qudsi Hadiths: A Default Semantics-Theoretic Perspective}

which undergo linguistic analysis in this paper are collected from Islamic scriptures.

\section{Analysis}

This section presents an analysis of BCs in the selected texts of the Holy Quran and the Qudsi Hadith. These conditionals have linguistically been manifested both directly and indirectly. The two types will be presented here.

\subsection{BCs in the Holy Quran}

\subsubsection{Direct BCs: Conditional forms with non-conditional meanings}

The first type of BCs in the Holy Quran is presented directly: they have conditional structures but communicate non-conditional meanings as is shown in the following extracts.

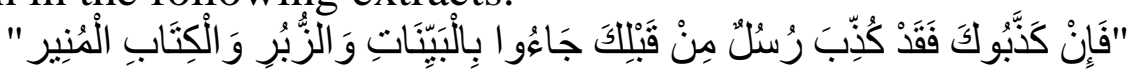

(1) "And if they deny thee, even so did they deny messengers who were before thee." (Al-e-Imran, 184)

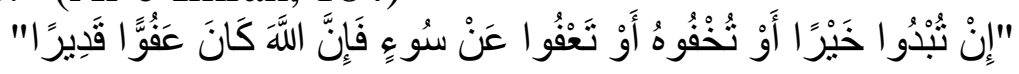

(2) "If ye do good openly or keep it secret, or forgive evil, lo! Allah is ever Forgiving, Powerful.” (An-Nisa, 149)

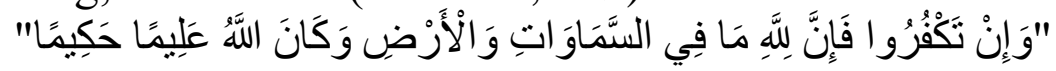

(3) "If ye disbelieve, still, lo! unto Allah belongeth whatsoever is in the heavens and the earth. Allah is ever Knower, Wise." (An-Nisa, 170)

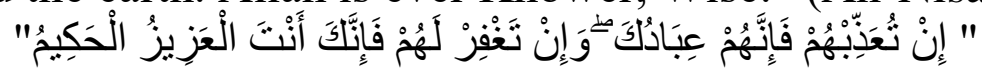

(4) "If Thou punish them, lo! they are Thy slaves, and if Thou forgive them (lo! they are Thy slaves). Lo! Thou, only Thou, art the Mighty, the Wise. (Al-Maeda, 118)

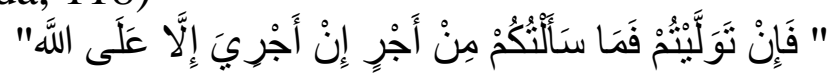

(5) "But if ye are averse I have asked of you no wage. My wage is the concern of Allah only." (Yunus, 72)

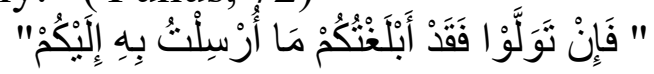

(6) "And if ye turn away, still I have conveyed unto you that wherewith I was sent unto you" (Hud, 57).

The above extracts demonstrate direct BCs structures with two clauses: the if-clause (the antecedent) and the main clause (the consequent). These conditional structures show a complete independence of the consequent from the antecedent. That is, the truth of their consequents does not depend on the truth of their antecedents. In other words, the if-clauses in the above extracts do not carry out the ordinary conditional function concerning the consequent clauses. The antecedents in (1-6), unlike hypothetical conditionals, do not specify the situations in which their consequents are true. Thus, the propositions communicated 


\section{Ayman F. Khafaga}

by the consequents in all of the above extracts are true whether or not the propositions conveyed by their antecedents are true.

Accordingly, the consequents in (1-6) are asserted independently of the truth of their antecedents. In (1), the situations in which the addressee (Prophet Muhammad) is denied do not specify the situations in which other messengers have been denied before. The truth of the consequent is not contingent on that of the antecedent. The same holds true for the verses (2-6); that is, doing good openly or keeping it secret in (2); the disbelief in Allah in (3); the state of punishing people or forgiving them in (4); the state of being averse in (5); and the state of turning away from the prophet's message in (6) do not specify the situations in which Allah is ever Forgiving and Powerful in (2); Allah has a complete possession over the Heavens and the Earth in (3); Allah's creatures are His slaves in (4); the prophet's wage is the concern of Allah only in (5); and the prophet has already conveyed his message to his people in (6).

Now, despite their surface conditional forms, the above texts lack conditionality due to the truth independence (propositions independence) holds between the two clauses (antecedents/consequents) which, for Franke (2007, p. 93), is "epistemic" in nature; that is, it depends on "the epistemic state of the speaker" (ibid., p. 92). Given that the relationship between discourse participants is a God-servants one, and that the truthfulness or falsity of the proposition in the antecedents in (1-6) does not influence or change the truth conditions of the proposition in their consequents, it follows then that the above examples do not communicate conditional meanings, and, therefore, other primary meanings are intended beyond their superficial conditional structures. Consequently, in order to arrive at the intended meanings in these examples, there is a need for other sources of information that enable us to generate such meanings, on the one hand, and to discover the other discourse functions conveyed by these texts, on the other. This target can semantically be realized by a merger representations analysis within the scope of Default Semantics theory.

By applying a merger representations analysis in light of Default Semantics processing model, this paper attempts to: (i) offer biscuit readings to the selected texts; (ii) arrive at the non-conditional primary meanings these texts carry; and (ii) identify discourse functions beyond their superficial conditionality. For example, in extract (1), repeated below again,

(1) "And if they deny thee, even so did they deny messengers who were before thee,"

we notice that the sentence communicates different readings. These assumed readings (interpretations) are called "default meanings" 


\section{When Conditionals Lack Conditionality: The Semantics of Biscuit Conditionals in some Selected Texts from the Holy Quran and the Qudsi Hadiths: A Default Semantics-Theoretic Perspective}

(Jaszczolt, 2005, p. 40) that can be realized by means of merger representations analysis which depends on certain sources of information (see Subsection 2.4) that interact to arrive at the intended meaning beyond the surface conditional structures of the sentence. Here, Allah does not want to tell His prophet that there are other messengers who are denied before him. However, He wants to relieve the prophet's sadness so as to endure patiently for the sake of the Heaven's message. The following figure shows how (1) conveys didactic religious meanings in light of merger representations analysis and within the processing model of Default Semantics.

\section{Sentence}

(1) "And if they deny thee, even so did they deny messengers who were before thee."

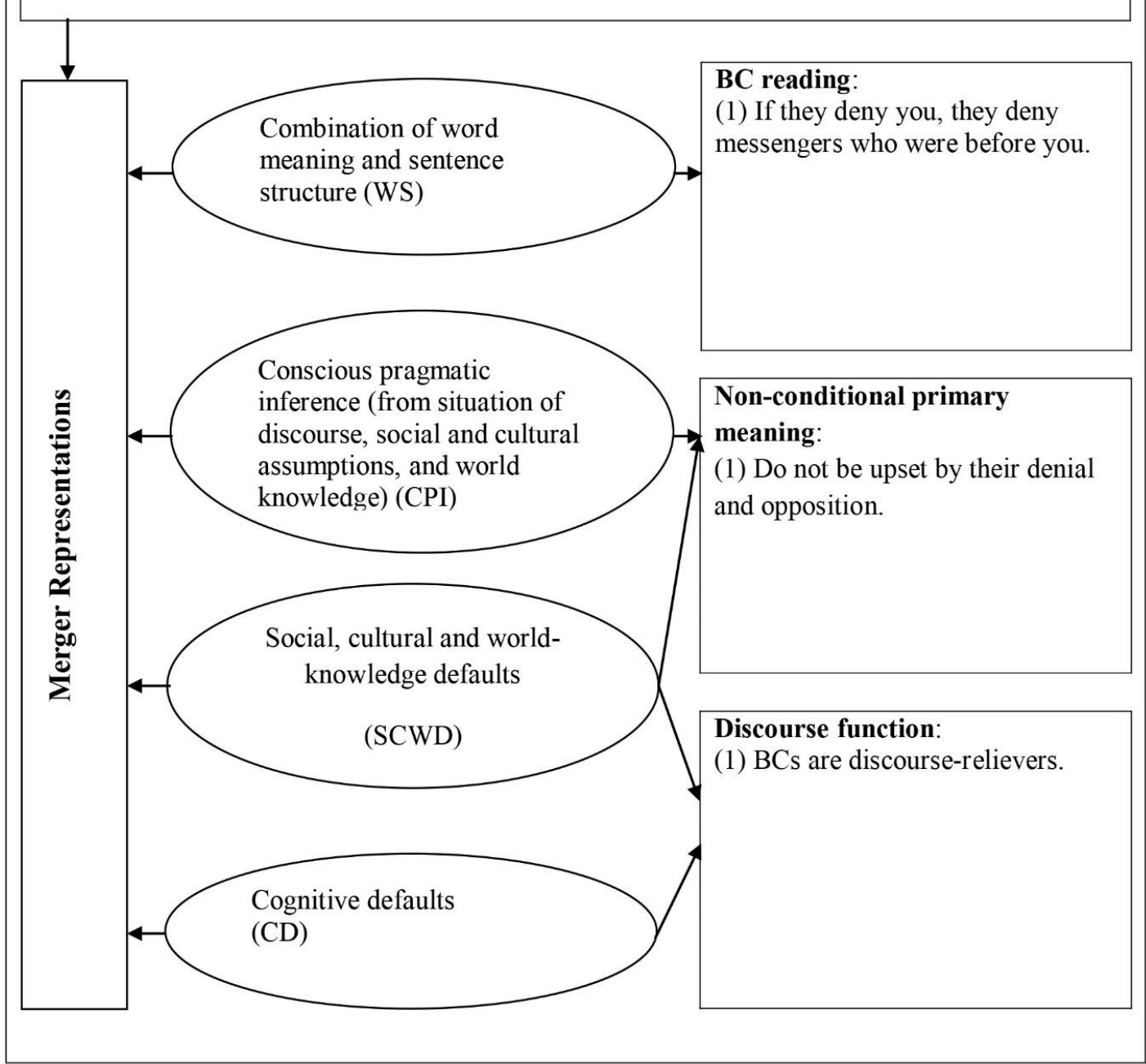

Figure 1: Interpretation of sentence (1) in Default Semantics processing model

Figure 1 above demonstrates the following default readings for (1): 
BC reading: If they deny you, they deny messengers who were before you (WS).

Non-conditional meaning: Do not be upset by their denial and opposition (SCWD \& CPI).

Discourse function: BCs are discourse-relievers (SCWD \& CD).

The above readings demonstrate the way through which a direct conditional sentence defaults to discourse function other than conditionality to serve didactic religious purposes. The non-conditional meaning in (1) is arrived at by means of merger representations analysis. As indicated in the figure, the combination of word meaning and sentence structure source (WS) helps identify the biscuit conditional reading of the sentence which in turn drives the default interpretation to arrive at the primary intended meaning by means of conscious pragmatic inference source (CPI) and social, cultural and world-knowledge defaults (SCWD). Out of the non-conditional meaning and by using of both social, cultural and world-knowledge defaults (SCWD) and cognitive defaults (CD), a discourse function other than conditionality is recognized: BCs are not conditionals but discourse-relievers.

Likewise, sentences (2-6) above, in light of Default Semantics processing model, and by means of merger representations analysis, can have the following default interpretations:

Default readings for (2)

BC reading: If you do good things openly or keep them secret, or forgive evil, Allah is ever forgiving, powerful (WS).

Non-conditional meaning: Allah knows what you show and what you hide (SCWD \& CPI).

Discourse function: BCS are fact-confirmers (SCWD \& CD).

Default readings for (3):

BC reading: If you disbelieve, Allah has whatsoever in the Heavens and the Earth (WS).

Non-conditional meaning: Allah has the complete power and authority over us (SCWD \& CPI).

Discourse function: BCs are fact-confirmers (SCWD \& CD).

Default readings for (4):

BC reading: If you punish or forgive them, they are your slaves (WS).

Non-conditional meaning: Allah is the only One Who can punish and forgive (SCWD \& CPI).

Discourse function: BCs are sympathy-instigators (SCWD \& CD).

Default readings for (5):

BC reading: If you are averse, I don't ask you a wage (WS).

Non-conditional meaning: I conveyed my message for the sake of Allah (SCWD \& CPI). 


\section{When Conditionals Lack Conditionality: The Semantics of Biscuit Conditionals in some Selected Texts from the Holy Quran and the Qudsi Hadiths: A Default Semantics-Theoretic Perspective}

Discourse function: $\mathrm{BCs}$ are information-notifiers (SCWD \& CD).

Default readings for (6):

BC reading: If you turn away, I have conveyed my message to you (WS).

Non-conditional meaning: I conveyed my message to you (SCWD \& CPI).

Discourse function: BCs are information-notifiers (SCWD \& CD).

The following figure clarifies how the above default readings of (2-6) are generated by merger representations analysis.

\section{Sentence:}

(2) "If ye do good openly or keep it secret, or forgive evil, lo! Allah is ever Forgiving,

Powerful."

(3) "If ye disbelieve, still, lo! unto Allah belongeth whatsoever is in the heavens and the earth."

(4) "If Thou punish them, lo! they are Thy slaves, and if Thou forgive them. Lo! Thou, only Thou, art the Mighty, the Wise."

(5) "But if ye are averse I have asked of you no wage."

(6) "And if ye turn away, still I have conveyed unto you that wherewith I was sent unto you."

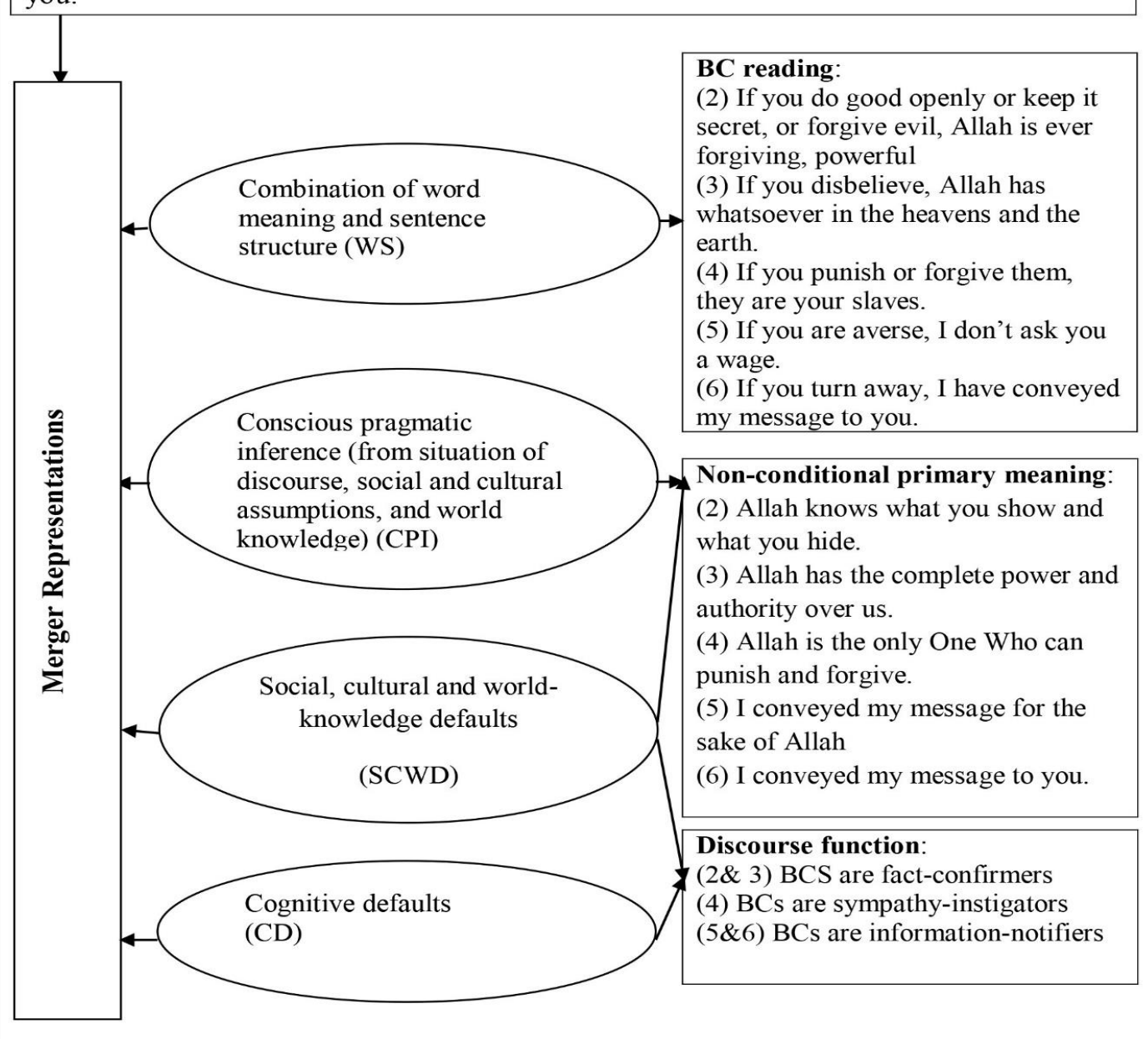

Figure 2: Interpretation of sentences (2-6) in Default Semantics processing model 
Figure 2: Interpretation of sentences (2-6) in Default Semantics processing model

Figure (2) above shows the different interpretations pertaining to sentences (2-6) that are realized by different sources of information within Default Semantics processing model. The figure clarifies that sentences (2-6) violate conditionality towards other discourse functions in which Biscuit Conditionals are perceived as fact-confirmers (2-3), sympathy-instigators (4), and information-notifiers (6). These discourse functions tend to validate the non-conditional primary meanings that address religious didacticism. Here, we notice that the intended nonconditional meanings of (2-6) are captivated by the default cognitive knowledge that is activated by the social and the cultural information on the part of hearers. This in turn emphasizes the relation between thought and natural language in linguistic communication.

\subsubsection{Indirect BCs: Non-conditional forms with non-conditional meanings}

The second type of BCs in the Holy Quran is indirectly expressed as is demonstrated in the following extracts.

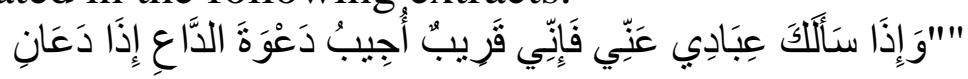

(7) "And when My servants question thee concerning Me, then surely I am nigh. I answer the prayer of the suppliant when he crieth unto Me." (AL-Baqara, 186)

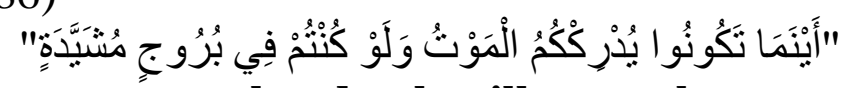

(8) "Wheresoever ye may be, death will overtake you, even though ye were in lofty towers." (AN-Nisa, 78)

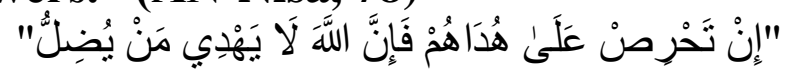

(9) "Even if thou [O Muhammad] desirest their right guidance, still Allah assuredly will not guide him who misleadeth." (An-Nahl, 37)

The above sentences show indirect BCs constructions that constitute non-conditional forms and communicate non-conditional meanings. Here, indirect conditionality is conveyed by means of 'when', 'even though' and even if' in (7), (8) and (9), respectively. Although 'when' expresses time conjunction in (7), 'even though' introduces contradictory propositions in (8), and 'even if' carries a hypothetical proposition, the three sentences are considered Biscuit Conditionals in the sense that the propositional truth of their main clauses (consequents) is not contingent on that of their if-clauses (antecedents). That is, the consequents seem to be entailed regardless of the truth/falsity of the antecedents. Thus, if we perceive (7), (8) and (9) as an ordinary types of conditionals, then they communicate the unlikely meanings that Allah's nearness to His servants in (7), escaping death in (8) and 


\section{When Conditionals Lack Conditionality: The Semantics of Biscuit Conditionals in some Selected Texts from the Holy Quran and the Qudsi Hadiths: A Default Semantics-Theoretic Perspective}

misguiding the misled in (9) are dependent upon asking about Allah, living in lofty towers and the desire of guiding people to the right path, respectively. However, in their biscuit perspective, the consequents of (79) are perceived as being truth-conditionally appropriate or relevant whether or not the addressees are concerned with the propositions in the antecedents. Consequently, applying a merger representations analysis to these sentences can generate certain religious didactic meanings as is clarified in the following figure.

\section{Sentence:}

(7) "And when My servants question thee concerning Me, then surely I am nigh."

(8) "Wheresoever ye may be, death will overtake you, even though ye were in lofty towers."

(9) "Even if thou [O Muhammad] desirest their right guidance, still Allah assuredly will not guide him who misleadeth."

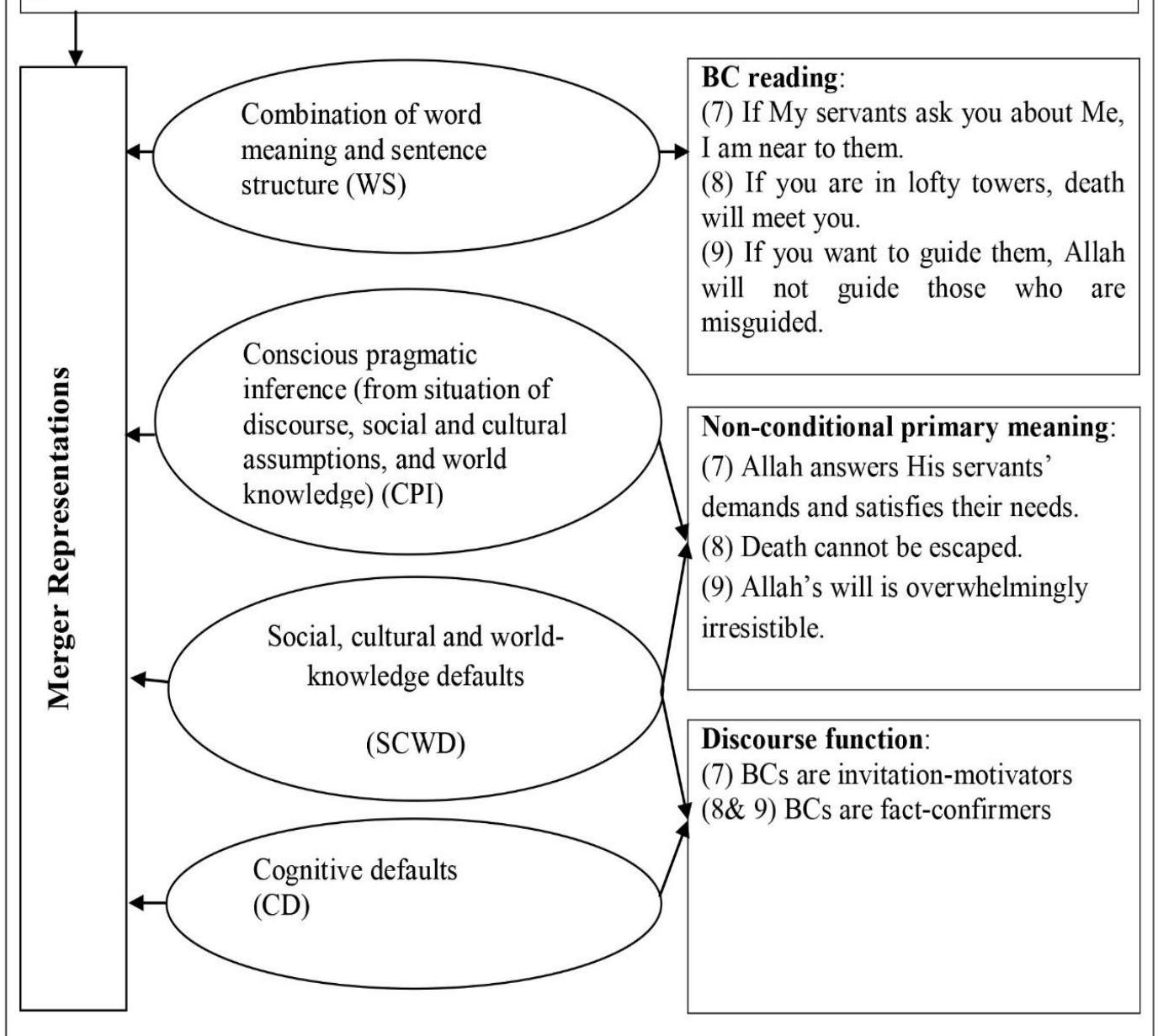

Figure 3: Interpretation of sentences (7-9) in Default Semantics processing model

Figure 3 above shows the different interpretations pertaining to sentences (7-9) as follows: 


\section{Ayman F. Khafaga}

Figure 3: Interpretation of sentences (7-9) in Default Semantics processing model

Figure 3 above shows the different interpretations pertaining to sentences (7-9) as follows:

Default readings for (7)

BC reading: If My servants ask you about Me, I am near to them (WS).

Non-conditional meaning: Allah answers His servants' demands and satisfies their needs (SCWD \& CPI).

Discourse function: BCs are invitation-motivators (SCWD \& CD).

Default readings for $(8)$ :

BC reading: If you are in lofty towers, death meets you (WS).

Non-conditional meaning: Death cannot be escaped (SCWD \& CPI).

Discourse function: BCs are fact-confirmers (SCWD \& CD).

Default readings for (9):

BC reading: If you want to guide them, Allah will not guide those who are misguided (WS).

Non-conditional meaning: Allah's will is overwhelmingly irresistible (SCWD \& CPI).

Discourse function: BCs are fact-confirmers (SCWD \& CD).

The above figure also displays the different sources of information that contribute in the realization of the biscuit reading of sentences (7-9), the non-conditional meanings they communicate and the discourse functions they carry. As demonstrated in the figure, the biscuit reading of the three sentences come as a result of a combination of word meaning and sentence structure; the non-conditional meanings are arrived at by means of conscious pragmatic inference and the social and cultural knowledge of the hearers; and the discourse function these sentences convey are recognized by virtue of an interaction between social, cultural and world-knowledge defaults and cognitive defaults.

\subsection{BCs in the Qudsi Hadith}

\subsubsection{Direct BCs: Conditional forms with non-conditional meanings}

A number of direct BCs have been marked in the selected Qudsi Hadith as is shown in the following extracts:

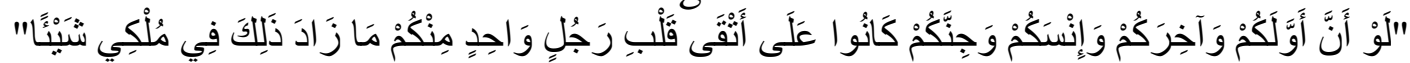

(10) "Were the first of you and the last of you, the human of you and the jinn of you to be as pious as the most pious heart of any one man of you, that would not increase My kingdom in anything."

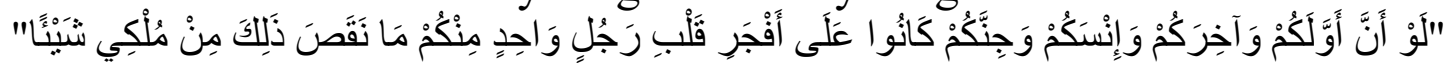
(11) "Were the first of you and the last of you, the human of you and the jinn of you to be as wicked as the most wicked heart of any one man of you, that would not decrease My kingdom in anything." 


\section{When Conditionals Lack Conditionality: The Semantics of Biscuit}

Conditionals in some Selected Texts from the Holy Quran and the Qudsi Hadiths: A Default Semantics-Theoretic Perspective

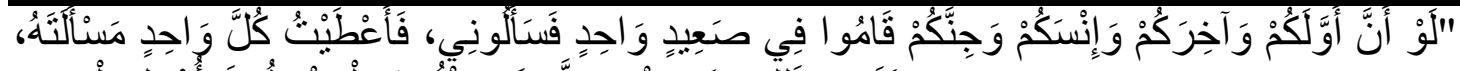

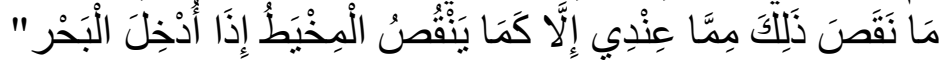

(12) "Were the first of you and the last of you, the human of you and the jinn of you to rise up in one place and make a request of Me, and were I to give everyone what he requested, that would not decrease what I have, any more that a needle decreases the sea if put into it."

The above extracts also display direct conditional structures in which the truth of the propositions encoded in their consequents do not depend on the truth of the propositions carried by their antecedents. This is clearly shown from the proposition independence between the antecedents and the consequents. Thus, the state of being pious or not in (10), of being wicked or not in (11) and of answering all requests of people in (12) do not affect the truth of the proposition that Allah's kingdom does not increase or decrease by the piousness or wickedness of His slaves. This didactic purpose drives the interpretative nature of BCs towards discourse functions other than conditionality. Noticeably, in (10) and (11), Biscuit Conditionals discursively operate as fact-confirmers. They are used to confirm the fact that the piousness and/or wickedness of the humans do not benefit or harm Allah. Further, in (12), the biscuit conditional functions as an invitation-motivator in which Allah invites His servants to continue asking Him to meet their needs because answering all their requests will never decrease what $\mathrm{He}$ possesses. Consequently, the consequents in (10-12) communicate more than what is actually asserted. What is conversationally evoked is the confirmation of the fact that our piousness and /or wickedness will never benefit or harm Allah. However, what is literally asserted is that Allah's kingdom will never increase or decrease by the humans' obedience or disobedience. Now, let us see how default meanings of (10-12) are captured by means of merger representations analysis as shown in the following figure. 


\section{Ayman F. Khafaga}

\section{Sentence:}

(10) "Were the first of you and the last of you, the human of you and the jinn of you to be as pious as the most pious heart of any one man of you, that would not increase My kingdom in anything."

(11) "Were the first of you and the last of you, the human of you and the jinn of you to be as wicked as the most wicked heart of any one man of you, that would not decrease My kingdom in anything."

(12) "Were the first of you and the last of you, the human of you and the jinn of you to rise up in one place and make a request of $\mathrm{Me}$, and were I to give everyone what he requested, that would not decrease what I have, any more that a needle decreases the sea if put into it."

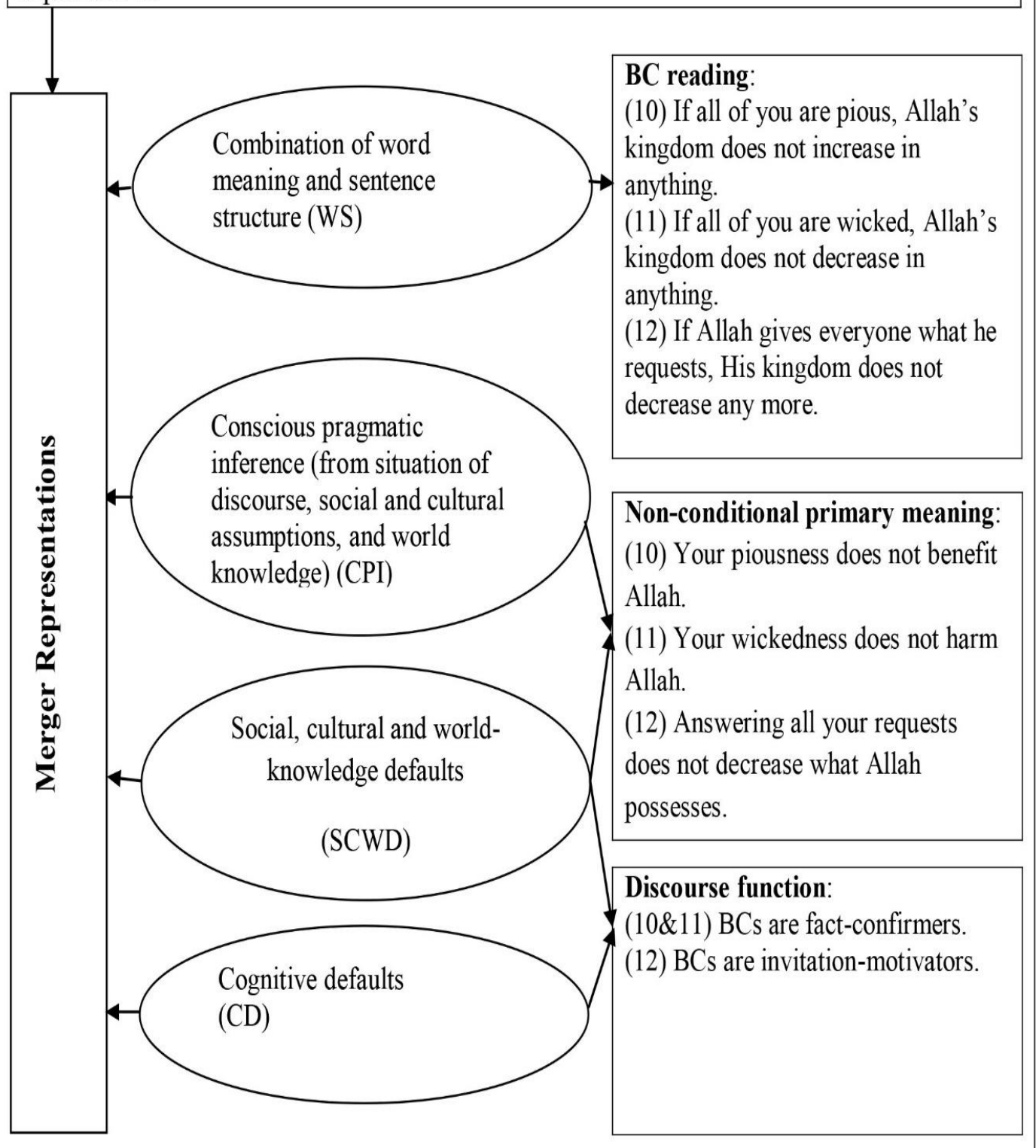

Figure 4: Interpretation of sentences (10-12) in Default Semantics processing model 


\section{When Conditionals Lack Conditionality: The Semantics of Biscuit Conditionals in some Selected Texts from the Holy Quran and the Qudsi Hadiths: A Default Semantics-Theoretic Perspective}

Figure 4: Interpretation of sentences (10-12) in Default Semantics processing model

As indicated in the above figure, sentences (10-12), within the processing model of Default Semantics and in light of merger representations, generate the following default readings.

Default reading of (10)

BC reading: If all of you are pious, Allah's kingdom does not increase in anything (WS).

Non-conditional meaning: Your piousness does not benefit Allah (SCWD \& CPI).

Discourse function: $\mathrm{BCs}$ are fact-confirmers (SCWD \& CD).

Default readings of (11)

BC reading: If all of you are wicked, Allah's kingdom does not decrease in anything (WS).

Non-conditional meaning: Your wickedness does not harm Allah (SCWD \& CPI).

Discourse function: BCs are fact-confirmers (SCWD \& CD).

Default readings of (12)

BC reading: If Allah gives everyone what he requests, His kingdom does not decrease any more (WS).

Non-conditional meaning: Answering all your requests does not decrease what Allah possesses (SCWD \& CPI).

Discourse function: $\mathrm{BCs}$ are invitation-motivators (SCWD \& CD).

\subsubsection{Indirect BCs: Non-conditional forms with non-conditional meanings}

Four constructions have been marked as carrying indirect Biscuit Conditionals in the selected Hadith. They are as follows:

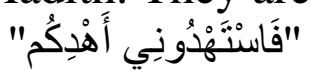

(13) "Seek guidance of Me and I shall guide you."

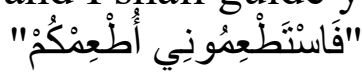

(14) "Seek food of Me and I shall feed you."

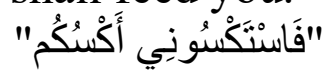

(15) "Seek clothing of Me and I shall clothe you."

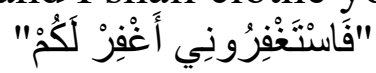

(16) "Seek forgiveness of Me and I shall forgive you."

A first look at the above sentences shows that they share some linguistic features: (i) all of them have the same syntactic construction; (ii) they communicate a conditional meaning of promises; (iii) they convey conditionality by means of an imperative mood through the imperative operator 'seek'; and (iv) the consequents are characterized by 
the truth modal 'shall'. To discuss how analytically these four constructions represent clear examples of $\mathrm{BCs}$, let us elaborate how such a superficially conditional constructions in (13-16) can be compositionally defaulted to communicate indirect $\mathrm{BCs}$ rather than any other types of conditionals (i.e. factual, indicative or subjunctive).

Superficially, the constructions in (13-16) show a conditional mood expressed by an imperative one. This is ordinarily perceived if we know that using imperatives is one way of expressing conditionality (Davies, 1986; von Fintel, 2011). Thus, they can be compositionally defaulted to generate the biscuit readings below:

(13a) Allah has the ability to guide you if you want to be guided.

(14a) Allah has the ability to feed you if you want to be fed.

(15a) Allah has the ability to clothe you if you want to be clothed.

(16a) Allah has the ability to forgive you if you want to be forgiven.

Such biscuit readings of (13a-16a) communicate a propositional independence between the antecedents and their consequents. That is, the consequents in (13a-16a) are asserted unconditionally. The ability of Allah to guide/ feed/ clothe and forgive His servants is not contingent on their seeking guidance/ food/ clothing/ and forgiveness of Him. This leads us to attribute non-conditional meanings to the above sentences as follows:

(13b) Help yourselves to guidance from Allah.

(14b) Help yourselves to food from Allah.

(15b) Help yourselves to clothing from Allah.

(16b) Help yourselves to forgiveness from Allah.

Obviously, based on default readings in (13a-16a) and their nonconditional meanings in (13b-16b), one can notice that the indirect conditionals in (13-16) are Biscuit Conditionals that operate in the discourse of the selected Hadith as offers-activators. Allah offers his guidance/ food/ clothe and forgiveness to His servants. The realization of these divine offers is not conditional upon the act of seeking them. This didactic meaning can be recognized by means of socio-cultural defaults as well as pragmatic inference; that is, all people are fed and clothed despite the fact that among them are many who do not seek food or clothing from Allah. Obviously, (13-16) imply that Allah assumes only a small distance between Him and the addressees. The following figure clarifies how merger representations sources help identify the biscuit conditional readings, the non-conditional meanings and the discourse function in (13-16). 
When Conditionals Lack Conditionality: The Semantics of Biscuit Conditionals in some Selected Texts from the Holy Quran and the Qudsi Hadiths: A Default Semantics-Theoretic Perspective

\section{Sentence:}

(13) "Seek guidance of Me and I shall guide you."

(14) "Seek food of Me and I shall feed you."

(15) "Seek clothing of Me and I shall clothe you."

(16) "Seek forgiveness of Me and I shall forgive you."

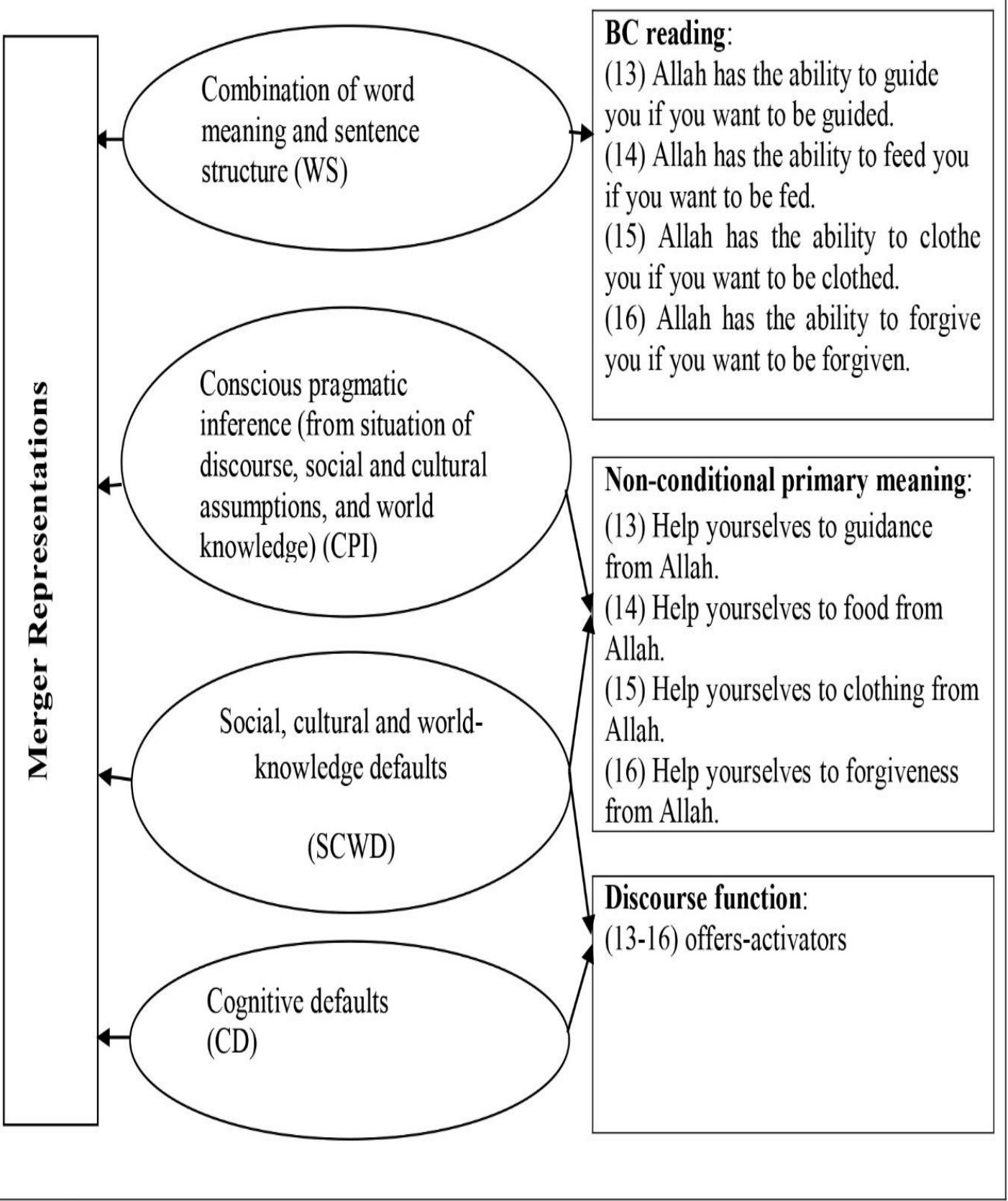

Figure 5: Interpretation of sentences (13-16) in Default Semantics processing model 
Figure 5: Interpretation of sentences (13-16) in Default Semantics processing model

The above figure demonstrates that certain sources of information contribute in generating the biscuit readings, non-conditional meanings and the discourse functions of (13-16). It also shows the significant part played by socio-cultural defaults and cognitive defaults in recognizing both the non-conditional meanings and the discourse functions of (13-16).

\subsection{Favoring one interpretation over another: The howness and whyness of non-conditional readings}

The above part of the analysis shows that the non-conditional interpretation of all Biscuit Conditionals comes as a result of the propositional independence that is noticed between the antecedents and the consequents. This independence feature emanates from the fact that the truth conditions in BCs' consequents are evident without any considerations to the truth or falsity of the propositions in the antecedents. For Franke (2007), this conditional independence derives the consequent entailment of Biscuit Conditionals towards non-conditional meanings which, according to Jaszczolt (2005), are reinforced by a number of contextual sources of information (merger representations).

The question now is: How is one interpretation (non-conditional meaning) favored over another? And why? Concerning the answer of the first part of our question, it is inherently related to the sources of information that constitute merger representations analysis (see Subsection 2.4). Sometimes, these non-conditional interpretations are pragmatically inferred from situation of discourse, social and cultural assumptions, and world knowledge. This pragmatic inference of specific non-conditional meanings is closely related to the other sources of information in merger representations analysis in the sense that it is often preceded by the process of biscuit readings which is realized through a combination of word meaning and sentence structure (WS), and followed by the stage in which discourse functions are recognized, which is motivated by both the social, cultural and world-knowledge defaults (SCWD) and the cognitive defaults (CD). Thus, it is a systematic process which starts on the level of word and sentence structure and ends with the cognitive level of perceiving ideas, analyzing them and giving results. For example, in (1), repeated here again, "And if they deny thee, even so did they deny messengers who were before thee," the way through which we identify the non-conditional meaning (do not be upset by their denial and opposition), which is pragmatically inferred from discourse, is firstly preceded by identifying the biscuit reading for the sentence (if they deny you, they deny messengers who were before you), which is also decided by means of word meaning and sentence structure, and is followed by 


\section{When Conditionals Lack Conditionality: The Semantics of Biscuit Conditionals in some Selected Texts from the Holy Quran and the Qudsi Hadiths: A Default Semantics-Theoretic Perspective}

recognizing the discourse function communicated by the sentence (BCs are discourse-relievers), which is realized by social, cultural and worldknowledge defaults and cognitive defaults.

Obviously, the non-conditional meanings captured from the selected texts in (1-16) originate from a religious background that is found to be encoded in cultural, social and world knowledge features that are supposed to be a part in the addressees' religious schemata. Thus, a combination of socio-cultural defaults and cognitive defaults operate indicatively to arrive at the non-conditional meanings of BCs in (1-16). These non-conditional meanings emphasize the relationship between the speaker and the hearer. Since it is a relationship that takes place between Allah and His creatures, the expected meanings conveyed by such a mode of communication are supposed to deal with divine messages and didactic instructions that not only offer a better understanding to the act of communication between discourse participants, but also emphasize the concepts of assertion (Predelli, 2009; von Finel, 2011), relevance (van Canegem-Ardijns \& van Belle, 2008) and intelligibility (Frank, 2007) in BCs' consequents.

With respect to the second part of our question, that is, the whyness of favoring specific non-conditional meanings of Biscuit Conditionals in the selected data. This can linguistically be evidenced by some anaphoric and/or cataphoric expressions that immediately precede and/or follow the texts under investigation. Anaphorically, for example, our selected extracts in (10,11 and 12) are preceded by the sentence: "O My servants, you will not attain harming $\mathrm{Me}$ so as to harm $\mathrm{Me}$, and will not attain benefitting Me so as to benefit Me." Also sentences (13, 14, 15, and 16) are preceded by the sentence: "all of you are astray except for those I have guided," "all of you are hungry except for those I have fed," "all of you are naked except for those I have clothed," and "you sin by night and by day, and I forgive all sins," respectively. These anaphoric sentences drive the process of meaning compositionality towards the nonconditional meanings specified in our analysis.

As for the cataphoric evidence for favored compositionality, it is clearly evident in the selected verses in (1-9). For example, in (5) and (7), repeated here again,

(5) "But if ye are averse I have asked of you no wage. My wage is the concern of Allah only."

(7) "And when My servants question thee concerning Me, then surely I am nigh. I answer the prayer of the suppliant when he crieth unto Me." 
We noticed that the favored interpretation of non-conditional meanings of (5) and (7) is linguistically supported by the cataphoric sentences that immediately follow the biscuit constructions. Thus, "My wage is the concern of Allah only" in (5) and "I answer the prayer of the suppliant when he crieth unto Me" in (7) foreground the non-conditional meanings: 'I conveyed my message for the sake of Allah" in (5) and 'Allah answers His servants' demands and satisfies their needs' in (7).

Still, one might object to the idea of truth independence existed between the two clauses in BCs, particularly if he perceives Franke's (2007) argument that "learning one proposition to be true or false (where this was not decided before) is not enough evidence to decide whether the other proposition is true of false (where this was not decided before)" (p. 92, emphasis in original) as an evidence that undermines the compositional truth of the consequents in the texts under investigation. Conversely, Franke's words support this paper's claim since the truth conditions of the consequents are pragmatically inferred from the anaphoricized and/or cataphoricized sentences discussed above. Thus, based on Franke's (ibid.) argument that "a speaker who (i) speaks truthfully in asserting 'If $P, Q$ ', (ii) considers $P$ and $Q$ epistemically independent and (iii) considers $P$ at least possible must believe in $Q^{\prime \prime}$ (p. 93 , italics in original), we can conclude that the non-conditional meanings conveyed by the selected texts are the most appropriate meanings that can be attributed to BCs discussed in this paper. This is because BCs, in the context of this paper, occur within a religion-oriented type of communication, in which the relation between discourse participants is a God-man relation. Also, these non-conditional meanings of $\mathrm{BCs}$ are supported by the anaphoric and/or cataphoric evidence of compositionality and the principle of proposition independence that characterizes their antecedent-consequent relationship.

\section{Findings \&discussion}

In light of the aforementioned theoretical preliminaries and viewed from the above analysis, this paper demonstrates a number of findings as follows:

\subsection{BCs between the Holy Quran and the Qudsi Hadith: Similarities and dissimilarities}

Despite the fact that the Holy Quran is a divine revelation in both meaning and wording, while only the meaning in the Qudsi Hadith is from Allah and the words expressed those meanings are formulated by the prophet, the analysis records some similarities as well as dissimilarities between the two sources concerning the representation of didactic religious meanings beyond Biscuit Conditionals constructions. With regard to the similarities, both sources identify two types of BCs: 


\section{When Conditionals Lack Conditionality: The Semantics of Biscuit Conditionals in some Selected Texts from the Holy Quran and the Qudsi Hadiths: A Default Semantics-Theoretic Perspective}

first, BCs that have conditional forms but communicate non-conditional primary meanings (direct $\mathrm{BCs}$ ); and, second, BCs that have nonconditional forms and communicate non-conditional meanings (indirect BCs). Importantly, this classification comes to terms with Elder and Jaszczolt's (2016) classification of conditionals in the sense that direct and indirect BCs in this paper correlate with Elder and Jaszczolt's (C2) and (C4) categories of conditionals, respectively (see Subsection 2.5).

Despite the fact that both direct and indirect BCs communicate similar didactic religious purposes that address Allah's power, authority, complete knowledge, generosity, forgiveness, richness, will and capability, we notice that the former is more representative in the Holy Quran (7 out of 9 utterances), while the latter is more representative in the Qudsi Hadith (4 out of 7 utterances). Also, the discourse functions assigned by BCs in the two sources are not the same. The Holy Quran, on the one hand, shows BCs as discourse-relievers in extract (1), factconfirmers in $(2,3,8,9)$, information-notifiers in $(5,6)$, invitationmotivators in (7), and sympathy-instigators in (4). The Qudsi Hadith, on the other hand, demonstrates BCs as fact-confirmers in $(10,11)$, invitation-motivators in (12), and offers-activators in $(13,14,15,16)$.

Further, the mood through which BCs are incorporated within didactic discourse differs in the two sources (i.e. the Quran and the Hadith). While it is directly declarative in the Holy Quran, it is characterized by antithetical words encapsulated by declarative and/or imperative moods in the Qudsi Hadith. Thus, we find BCs whose meanings are directly addressed to hearers/readers in the Holy Quran as in (1-9); and other BCs whose meanings are featured with opposites in the Qudsi Hadith, such as astray/guided, hungry/fed, naked/clothed, sin/forgive, harming/benefitting, first/last, human/jinn, pious/wicked and increase/decrease. Significantly, these antithetical words have a role to play in meaning compositionality of BCs in the Qudsi Hadith. That is because they represent a part in one of the merger representations sources of information that functions to generate the intended meaning of the speaker in Default Semantics: the combination of word meaning and sentence structure (WS).

\subsection{Non-conditional readings of BCs: Conditionality is missed}

The above analysis supports the assumption that BCs are conditionals that lack conditionality in the sense that they semantically default to nonconditional meanings. This paper, therefore, correlates with Austin's 


\section{Ayman F. Khafaga}

(1961) argument that Biscuit Conditionals are not conditionals. Violating conditionality is an inherent characteristic of all BCs in the selected data. They cease to be conditionals and become discursive tools for communicating religiously didactic messages. The paper also reconciles with Predelli's (2009) view that the compositional truth of the consequents in BCs are not contingent on that of the antecedents. This is linguistically evidenced in the analysis of the selected data by the truthconditionally independence of the consequents. The propositions conveyed by the consequents in all BCs constructions under investigation are true without any consideration to the truth or falsity of their antecedents. Further, the paper agrees to Bhatt \&Pancheva's (2005, p. 671) claim that the antecedent of a biscuit conditional "specifies the circumstances in which the consequent is discourse-relevant, not the circumstances in which it is true." Significantly, this relevant relationship between if-clauses (antecedents) and main clauses (consequents) in BCs proves useful in recognizing the primary intended meanings beyond this type of conditionals.

Also, in view of what the analysis of this paper demonstrates, BCs invite an 'if (not) $p$, $q$ ' reading, which goes in accordance with much of the literature on BCs (e.g., Iatridou, 1991; von Fintel, 1997, 2011; Siegel, 2006; Franke, 2007; Predelli, 2009; Schulz, 2015; Rieser, 2017). Consequently, as shown in the above analysis, BCs do not convey a condition, but rather they "operate in a higher speech act level" (von Fintel, 2011, p. 1517). This speech act level is communicated from the semantic compositionality of this type of conditionals. That is, different discourse functions are conveyed by means of using BCs in the selected data. Within the discourse of religious didacticism, BCs are employed to instruct a message; sometimes in the form of invitations or offers, and in other cases by stating a fact, confirming a piece of information, relieving discourse or instigating sympathy.

\subsection{Default Semantics is theoretically relevant to the study of BCs}

The analysis demonstrates the relevance of Default Semantics to the study of acts of communications (utterances). As shown in this paper, this theory of discourse meaning proves useful in generating the nonconditional intended meanings beyond the surface conditional (direct/indirect) forms of BCs. This is conducted within the processing model of Default Semantics and in light of a merger representations analysis activated by certain sources of information that help to identify a non-conditional interpretation for BCs in the selected data. Since Default Semantics is "a compositional approach to natural language meaning" (Elder \& Jaszczolt, 2005, p. 47), which is derived from the interaction of different sources of information other than surface linguistic forms, it can 


\section{When Conditionals Lack Conditionality: The Semantics of Biscuit Conditionals in some Selected Texts from the Holy Quran and the Qudsi Hadiths: A Default Semantics-Theoretic Perspective}

be said then that this theory of discourse meaning is relevant to the study of BCs because it aims to "view the conditional as a semantic and cognitive universal that is operative in human thought and is present in the semantic representation of natural language sentences as they are used in communication" (ibid., p. 47).

Accordingly, Jaszczolt's (2005) Default Semantics contradicts with Borg's $(2004,2012)$ Minimalism that focuses only on the literal meaning of the sentence that is taken on by the lexical-semantic features of the words in a sentence without consideration to the other surrounding factors that affect the interpretation of sentences. In Jaszczolt's view, meanings are semantically composed before context information comes into play. Based on a radical contextual view of sentence interpretation, Default Semantics takes into account different contextual effects in order to arrive at the intended meanings pertaining to utterances. Among these elements are the cognitive default principles, truth conditions, compositional rules, and five basic contextual information sources (see Subsection 2.4). For Jaszczolt (2016), the meaning of sentences can be seized by the combination of contextual information and compositional knowledge of sentences in linguistic communication. Thus, Default Semantics is relevant not only to the study of BCs in the selected texts, but also to any type of texts that communicate meanings other than what is expressed in their surface structure.

\subsection{Cataphoric /anaphoric evidences of compositionality}

The analysis revealed that the non-conditional primary meanings communicated by $\mathrm{BCs}$, which are recognized by means of a merger representations analysis, are not only generated by the sources of information listed by Jaszczolt (2005) (see Subsection 2.4). These meanings, which violate conditionality, are anaphorically and/or cataphorically activated by what Jaszczolt (ibid., p. 157) calls "anaphoric defaults"; that is, some linguistically pre-posed and/or post-posed expressions operate as meaning acceptability motivators that function to prioritize one primary meaning over another. Significantly, the analysis demonstrates that the anaphorically expressions are analytically highlighted only in BCs in the selected Qudsi Hadith, whereas their counterparts (i.e. the cataphoric expressions) are indicative in the $\mathrm{BCs}$ selected from the Holy Quran.

Crucially, Jaszczolt's (2005) anaphoric/(cataphoric) defaults, which offer a semantic support for meaning compositionality of BCs addressed here, goes in conformity with Du Bois's (2014) cognitive dialogic view, in which he advocates the idea that the meaning of one sentence is 


\section{Ayman F. Khafaga}

appropriately captured in terms of its relation with the neighboring sentences within the linguistic communication. Also, this anaphoric/cataphoric support of primary meaning in BCs interpretation comes to terms with what Recanati (2004) calls availability condition, which emphasizes that the addressees' inference to arrive at certain primary meanings depends on ideas that are inferred from earlier construction. This paper, therefore, correlates with $\mathrm{Du}$ Bois's and Recanati's arguments that inferences made by hearers are supported by ideas that are previously and/or subsequently mentioned in discourse. However, it goes in the opposite direction to Levinson's (2000, p. 27) "preferred interpretation" that utterance meanings (intended meanings) can be arrived at by the structure of the utterance and without any contextual clues. Thus, the anaphoricized/ cataphoricized motivation of meaning enables hearers to recognize the intended meanings BCs initiate. In other words, they provide readers/hearers with "enough evidence to make the claim" (Al-Khatib, 2012, p. 487), which functions to make them able to "have a firsthand experience of his/her rights and obligations" towards the addressed topic (ibid., p. 487).

Finally, social and cultural contexts have a significant role to play in the linguistic investigation of any text, particularly if this text is religionoriented. The socio-cultural information as one part among the sources of information within merger representations analysis (Jaszczolt, 2005), with the religious background as one of its aspects, helps readers/hearers arrive at specific default interpretations. This culturally religious background makes hearers "discursively equipped" with enough information "prior to the encounter with the text" (Fowler, 1996, p. 7). In light of this paper, this prior acquaintance on the part of readers/hearers drives the interpretation process of the selected texts towards a non-conditional biscuit reading that serves discourse functions other than conditionality. 


\section{When Conditionals Lack Conditionality: The Semantics of Biscuit Conditionals in some Selected Texts from the Holy Quran and the Qudsi Hadiths: A Default Semantics-Theoretic Perspective}

\section{Conclusion}

This paper investigated Biscuit Conditionals in some selected texts from the Holy Quran and the Qudsi Hadith. The paper manages, through the linguistic analysis of the selected data, to answer its main research questions. Concerning the research question No.1: what are the different types of BCs presented in the selected texts of the Holy Quran and the Qudsi Hadith? The analysis displayed two types of Biscuit Conditionals in the selected data: direct and indirect. The first type, however syntactically conditional, communicates non-conditional meanings. The second type is marked by both non-conditional structures and nonconditional meanings.

As for the research question No.2: why are the selected constructions considered BCs, not any other type of conditionals? It is linguistically evidenced in the analysis that all conditional constructions investigated here are true BCs for two reasons: first, they constitute two parts; ifclauses parts (antecedents) and main clauses parts (consequents), in which the truth conditions of the consequents do not depend on that of the antecedents; and second, there is some sort of relevance between the antecedents of this type of conditionals and their consequents that validates the adherence to one specific non-conditional primary meaning, and, therefore, its acceptability on the part of hearers. The two reasons encompass the main semantic tenets of Biscuit Conditionals.

In terms of the research question No.3: what are the didactic purposes conveyed by $\mathrm{BCs}$ in the selected data? The analysis demonstrated that all $\mathrm{BCs}$ constructions in the selected data go beyond conditionality towards other discourse functions that aim to achieve particular didactic purposes that operate indicatively within a religious discourse setting. BCs in the selected data are information-notifiers, fact-confirmers, discourserelievers, sympathy-instigators, invitation-motivators and offer-activators. These functions target certain didactic religious concepts that address Allah's complete power, authority, knowledge, ability, determination and will.

Regarding the research question No.4: how are BCs semantically represented to convey non-conditional meanings within the framework of Default Semantics theory, and in light of a religion-oriented type of communication? The analysis showed that all sentences that are highlighted as carrying BCs in the selected data have undergone a merger representations analysis in which specific sources of information are summoned to arrive at the intended meanings. The analysis also revealed that merger representations analysis, being one main tool of generating 


\section{Ayman F. Khafaga}

primary meanings in Default Semantics, authenticates the core idea in this paper: how Biscuit Conditionals cease to communicate conditionality and become conduits of religious didacticism.

Finally, two points this paper suggests for future research. First, applying the same theoretical approach of Default Semantics to the analysis of conditionals in ordinary discourse (i.e. among equal power relations participants) might reveal different findings from those approached here. Second, another study of the semantics of both Canonical and Biscuit Conditionals in the Holy Quran and the Qudsi Hadiths might yield similar and/or different findings, particularly in relation to the different aspects of politeness and the way they operate semantically in religious discourse. 


\section{When Conditionals Lack Conditionality: The Semantics of Biscuit}

Conditionals in some Selected Texts from the Holy Quran and the Qudsi Hadiths: A Default Semantics-Theoretic Perspective

\section{References}

Al-Khatib, M. (2012). Politeness in the Holy Quran: A sociolinguistic and pragmatic perspective. Intercultural Pragmatics, 9(4), 479509.

https://doi.org/10.1515/ip-2012-0027

Austin, J. (1961 [1979]). Ifs and cans. In J. O. Urmson, \& G. J. Warnock (Eds.), Philosophical papers (pp. 153-180). Oxford: Oxford University Press.

Beck, S. (1997). On the semantics of comparative conditionals. Linguistics and Philosophy, 20, 229-271. https://doi.org/10.1023/A:1005361901518

Bennett, J. (2003). A philosophical guide to conditionals. Oxford: Oxford Unversity Press. https://doi.org/10.1093/0199258872.001.0001

Bhatt, R., \& Pancheva, R. (2005). Conditionals. In M. Everaert, H. van Riemsdijk, R. Goedemans, \& B. Hollebrandse (Eds.), The Blackwell companion to syntax (pp. 638-687). Malden, MA: Blackwell.

https://doi.org/10.1002/9780470996591.ch16

Borg, E. (2004). Minimal semantics. Oxford: Clarendon Press. https://doi: 10.1093/0199270252.001.0001

Borg, E. (2012). Pursuing meaning. Oxford: Oxford University Press. https://doi: 10.1093/acprof:oso/9780199588374.001.0001

Byrne, R. J., \& Johnson-Laird, P. N. (2010). Conditionals and possibilities. In M. Oaksford, \& N. Chater (Eds.). Cognition and conditionals: Probability and logic in human thinking (pp. 5568). Oxford: Oxford University Press. https://doi.org/10.1093/acprof:oso/9780199233298.003.0003

Capone, A. (2011). Default Semantics and the architecture of the mind. Journal of Pragmatics, 43, 1741-1754. http:// doi:10.1016/j.pragma.2010.11.004

Dancygier, B. (1998). Conditionals and predictions: Time, knowledge, and causation in conditional constructions. Cambridge: Cambridge University Press. https://doi.org/10.1017/CBO9780511486463 
Davies, E. (1986). The English imperative. London: Croom Helm.

Declerck, R., \& Reed, S. (2001). Conditionals: A comprehensive empirical analysis. Berlin. New York: Mouton de Gruyter. https://doi.org/10.1111/0029-4624.00161

DeRose, K., \& Grandy, R. E. (1999). Conditional assertions and biscuit conditionals. Noûs, 33(3), 405-420.

https://doi.org/10.1111/0029-4624.00161

Douven, I. (2012). Learning conditional information. Mind \& Language, 27(3), 239-263. https://doi.org/10.1111/j.14680017.2012.01443.x

Du Bois, J. W. (2014). Towards a dialogic syntax. Cognitive Linguistics, 25(3), 359-410. https://doi: 10.1515/cog-2014-0024

Elder, C., \& Jaszczolt, K. M. (2016). Towards a pragmatic category of conditionals. Journal of Pragmatics, 98, 36-53. https://doi.org/10.1016/j.pragma.2016.04.013

von Fintel, K. (1997). Bare plurals, bare conditionals, and only. Journal of Semantics, 14, 1-56. https://doi.org/10.1093/jos/14.1.1

von Fintel, K. (2009). Conditionals. Cambridge: Cambridge University Press.

von Fintel, K. (2011). Conditionals. In K. Heusinger, C. Maienborn,\& P. Portner (Eds.), Semantics: An international handbook of meanings (Vol. 2, pp. 1515-1538). Berlin/Boston: de Gruyter Mouton.

Fowler, R. (1996). On critical linguistics. In C. R. Caldas-Coulthard, \& M. Coulthard (Eds.), Texts and practices: Readings in critical discourse analysis (pp. 3-14). London: Routledge.

Francez, I. (2015). Chimerical conditionals. Semantics \& Pragmatics, 8 (2), 1-35. http://dx.doi.org/10.3765/sp.8.2

Franke, M. (2007). The pragmatics of biscuit conditionals. In M. Aloni, P. Dekker, \& F. Roelofsen (Eds.), Proceedings of the 16th Amsterdam Colloquium (pp. 91-96). Amsterdam: Palteam.

Iatridou, S. (1991). Topics in conditionals (Doctoral dissertation). Massachusetts Institute of Technology, Dept. of Linguistics and Philosophy.

Ibrahim, E., \& Johnson-Davies, D. (Trans.) (1976). An-Nawawi's Forty Hadith. Cairo: Al-Amal Publishing Company. Also available at: 


\section{When Conditionals Lack Conditionality: The Semantics of Biscuit}

Conditionals in some Selected Texts from the Holy Quran and the Qudsi Hadiths: A Default Semantics-Theoretic Perspective

https://kitaabun.com/shopping3/nawawis-forty-hadith-ibrahimjohson-davies-taqwa-p-3228.html

Jaszczolt, K. (2005). Default semantics: Foundations of a compositional theory of acts of communication. Oxford: Oxford University Press.

https://doi.org/10.1093/acprof:oso/9780199261987.001.0001

Jaszczolt, K. (2009). Cancellability and the primary/secondary meaning distinction. Intercultural Pragmatics, 6, 259-289. https://doi.org/10.1515/IPRG.2009.015

Jaszczolt, K. (2010). Default semantics. In B. Heine, \& H. Narrog (Eds.), The Oxford handbook of linguistic analysis (pp. 193-221). Oxford: Oxford University Press.

Jaszczolt, K. (2011). Salient meanings, default meanings and automatic processing. In K. Jaszczolt, \& K. Allan (Eds.), Salience and defaults in utterance processing (pp. 11-33). Berlin: Mouton de Gruyter.

Jaszczolt, K. (2016). Meaning in linguistic interaction: Semantics, metasemantics, philosophy of language. Oxford: Oxford University Press.

Joh, Y. (2011). Biscuit conditionals as disguised conversations. Korean Journal of English Language and Linguistics, 11(1), 243-268. https://doi.org/10.15738/kjell.11.1.201103.243

Kamp, H. (1981). A theory of truth and semantic representation. In J. Groenendijk, T. Janssen, \& M. Stokhof (Eds.), Formal methods in the study of language (pp. 277-322). Amsterdam: Mathematisch Centrum

Kidwai , A. R. (2017). Muhammad Marmaduke Pickthall's English translation of the Quran (1930): An assessment. In G. P. Nash (Ed.), Marmaduke Pickthall: Islam and the modern world (pp. 231-248). Leiden \&Boston: Brill. https://doi.org/10.1163/9789004327597_013 


\section{Ayman F. Khafaga}

Levinson, S. C. (2000). Presumptive meanings: The theory of generalized conversational implicature. Cambridge, MA: MIT Press. https://doi.org/10.7551/mitpress/5526.001.0001

Lycan, W. G. (2001). Real conditionals. Oxford: Clarendon Press.

Pickthall, M. M. (1930 [1985]). The meaning of the Holy Qur'an. Delhi: Crescent Publishing House.

Predelli, S. (2009). Towards a semantics for biscuit conditionals. Philosophical Studies, 142, 293-305. https://doi.org/10.1007/s11098-007-9187-8

Recanati, F. (2004). Literal meaning. Cambridge: Cambridge University Press. https://doi.org/10.1017/CBO9780511615382

Rhee, S. (2014). "I know you are not, but if you were asking me": On emergence of discourse markers of topic presentation from hypothetical questions. Journal of Pragmatics, 60, 1-16. http://dx.doi.org/10.1016/j.pragma.2013.10.005

Rieser, L. (2017). Truth conditionals and use conditionals: An expressive modal analysis. In S. Kurahashi, K. Satoh, Y. Ohta, D. Bekki, $\&$ S. Arai (Eds.), New frontiers of artificial intelligence (pp. 108122). Springer International Publishing AG. https://doi.org/10.1007/978-3-319-61572-1_8

Schulz, K. (2015). Conditionals from a linguistic point of view: Two case studies. Journal of Philosophical Logic, 44(6), 805-816. http://doi.org/ 10.1007/s10992-015-9361-y

Siegel, M. E.A. (2006). Biscuit conditionals: Quantification over potential literal acts. Linguistics and Philosophy, 29(2), 167-203. https://doi.org/10.1007/s10988-006-0003-2

Skovgaard-Olsen, N. (2016). Motivating the relevance approach to conditionals. Mind \& Language, 31(5), 555-579. https://doi.org/10.1111/mila.12120

Sperber D., \& Wilson D. (1995). Relevance: Communication and cognition (2nd ed.). Oxford: Basil Blackwell.

Swanson, E. (2013). Subjunctive biscuit and stand-off conditionals. Philosophical Studies, 163(3), 637-648. https://doi.org/10.1007/s11098-011-9836-9 


\section{When Conditionals Lack Conditionality: The Semantics of Biscuit}

Conditionals in some Selected Texts from the Holy Quran and the Qudsi Hadiths: A Default Semantics-Theoretic Perspective

van Canegem-Ardijns, I., \& van Belle, W. (2008). Conditionals and types of conditional perfection. Journal of Pragmatics, 40, 349-376. https://doi.org/10.1016/j.pragma.2006.11.007

van der Auwera, J. (1986). Conditionals and speech acts. In E. C. Traugott, A. ter Meulen, J. S. Reilly, \& C. A. Ferguson (Eds.), On conditionals (pp. 197-214). Cambridge: Cambridge University Press. https://doi.org/10.1017/CBO9780511753466.011

van der Auwera, J. (1997). Pragmatics in the last quarter century: The case of conditional perfection. Journal of Pragmatics 27, 261274.

https://doi.org/10.1016/S0378-2166(96)00058-6

Yule, G. (1998). Explaining English grammar. Oxford: Oxford University Press.

Zakkou, J. (2017). Biscuit conditionals and prohibited 'then'. Thought, 6, 84-92. https://doi.org/10.1002/tht3.235 